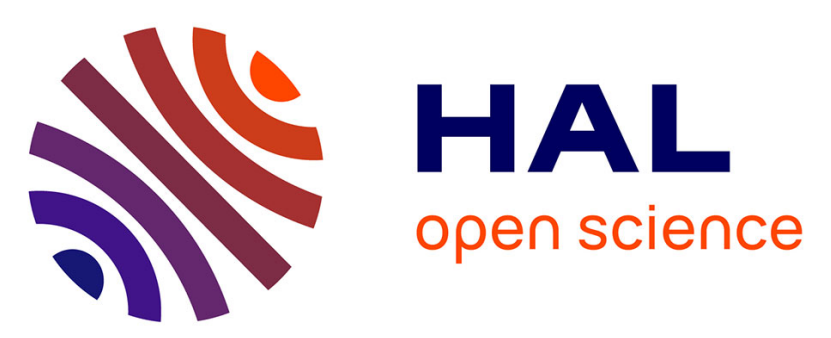

\title{
How to manage natural risks in mountain areas in a context of imperfect information? New frameworks and paradigms for expert assessments and decision-making
}

Jean-Marc Tacnet, Jean Dezert, Corinne Curt, Mireille Batton-Hubert, Eric

Chojnacki

\section{To cite this version:}

Jean-Marc Tacnet, Jean Dezert, Corinne Curt, Mireille Batton-Hubert, Eric Chojnacki. How to manage natural risks in mountain areas in a context of imperfect information? New frameworks and paradigms for expert assessments and decision-making. Environment Systems and Decisions, 2014, Volume 34 (Issue 2), pp 288-311. 10.1007/s10669-014-9501-x . emse-00995011

HAL Id: emse-00995011

https://hal-emse.ccsd.cnrs.fr/emse-00995011

Submitted on 23 Jan 2019

HAL is a multi-disciplinary open access archive for the deposit and dissemination of scientific research documents, whether they are published or not. The documents may come from teaching and research institutions in France or abroad, or from public or private research centers.
L'archive ouverte pluridisciplinaire HAL, est destinée au dépôt et à la diffusion de documents scientifiques de niveau recherche, publiés ou non, émanant des établissements d'enseignement et de recherche français ou étrangers, des laboratoires publics ou privés. 


\title{
How to manage natural risks in mountain areas in a context of imperfect information? New frameworks and paradigms for expert assessments and decision-making
}

\author{
Jean-Marc Tacnet · Jean Dezert • Corinne Curt • \\ Mireille Batton-Hubert • Eric Chojnacki
}

\begin{abstract}
In mountain areas, natural phenomena such as snow avalanches, debris flows and rock-falls, put people and objects at risk with sometimes dramatic consequences. Risk is classically considered as a combination of hazard, the combination of the intensity and frequency of the phenomenon, and vulnerability which corresponds to the consequences of the phenomenon on exposed people and material assets. Risk management consists in identifying the risk level as well as choosing the best strategies for risk prevention, i.e. mitigation. In the context of natural phenomena in mountainous areas, technical and scientific knowledge is often lacking. Risk management decisions are therefore based on imperfect information. This information comes from more or less reliable sources ranging from historical data, expert assessments, numerical simulations etc. Finally, risk management decisions are the result of complex knowledge management and reasoning processes. Tracing the information and propagating information quality from data acquisition to decisions are
\end{abstract}

J.-M. Tacnet $(\bowtie)$

Irstea, UR ETGR, 2 Rue de la Papéterie, BP 76,

38402 St-Martin-d'Hères, France

e-mail: jean-marc.tacnet@irstea.fr

J. Dezert

The French Aerospace Lab, Chemin de la Hunière,

91761 Palaiseau, France

\section{Curt}

Irstea, UR OHAX, 3275, Route Cezanne - CS 40061,

13182 Aix-en-Provence Cedex 5, France

M. Batton-Hubert

ENSMSE, 29, rue Ponchardier, 42100 Saint-Étienne, France

E. Chojnacki

IRSN, BP 3, 13115 Saint-Paul-Lez-Durance Cedex, France therefore important steps in the decision-making process. In this paper, a global integrated framework is proposed to improve the risk management process in a context of information imperfection provided by more or less reliable sources. It includes uncertainty as well as imprecision, inconsistency and incompleteness. It is original in the methods used and their association: sequential decision context description, development of specific decisionmaking methods, imperfection propagation in numerical modelling and information fusion. This framework not only assists in decision-making but also traces the process and evaluates the impact of information quality on decision-making.

Keywords Natural hazards - Mountains · Risk management · Expert assessment · Decision-making · Information imperfection · Uncertainty

\section{Introduction}

Natural phenomena in mountainous areas put people and assets at risk (e.g. Fig. 1). Risk is classically assessed as a combination of hazard and vulnerability in the natural hazard context (Eq. 1). Hazard relates to the intensity and frequency of phenomena, whereas vulnerability concerns damages and values assessment (of elements at risk $w$ ) and can be seen as a combination of exposure and potential losses.

$$
\text { Risk }=\sum_{\mathrm{W}}(\underbrace{\text { Hazard }}_{\text {Frequency } \otimes \text { Intensity }} \otimes \underbrace{\text { Vulnerability }}_{\text {Damage } \otimes \text { Value }})
$$

However, in practice, the basic risk equation must detail its components (Eq. 2) to consider both the different effects 


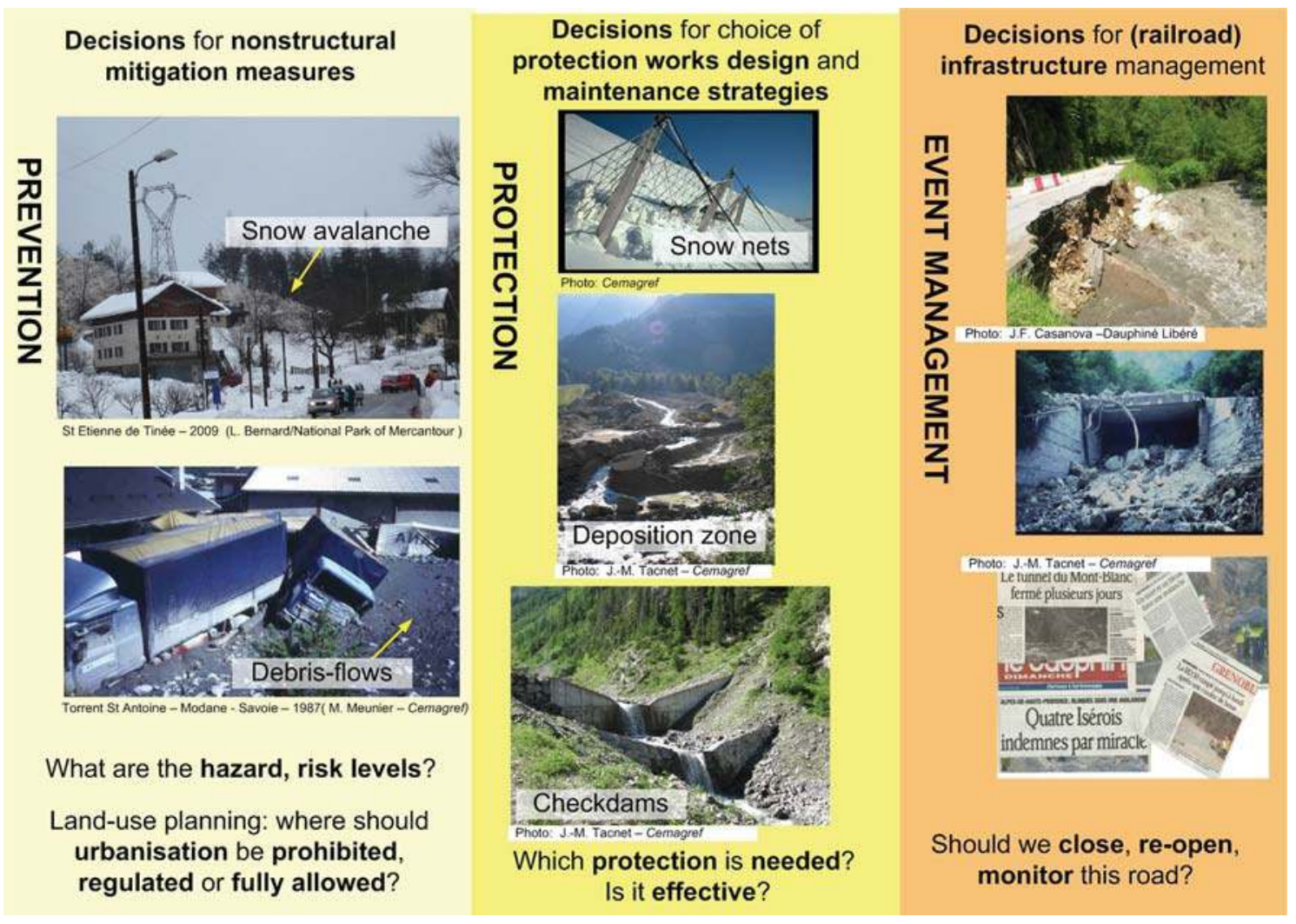

Fig. 1 Mountain risk management-related decision contexts

of a phenomenon (e.g. a torrent flood can induce several different types of damages due to impact on structures, scouring of foundations, submersion ) and also the period of exposure to risk (e.g. this period is different in a factory, a house, on a road).

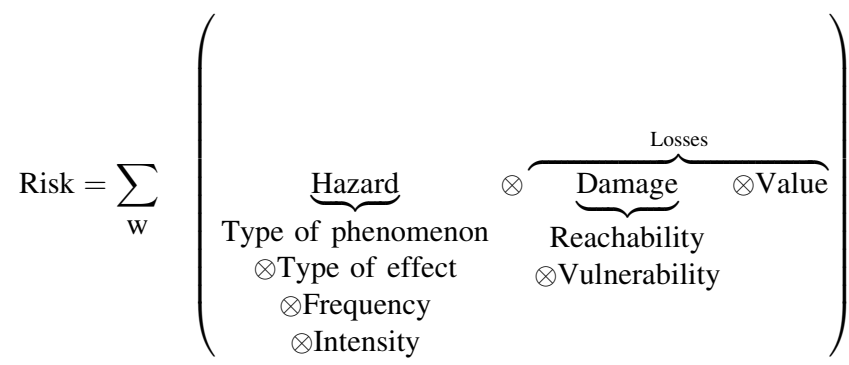

where (for a given phenomenon)

$w \equiv$ whole sets of elements at risk

Reachability $\triangleq$ Exposure $\otimes$ Presence

Vulnerability $\equiv$ Potential of loss
Risk prevention strategies are often based on structural measures such as protection works . It is therefore appropriate to also analyse and use industrial approaches dedicated to technological system failure analysis (see Sect. 3.6). In industrial contexts (Mortureux 2001), risk combines frequency and severity, but it can be seen here that the components of the equation are equivalent in these two contexts (Eq. 6).

Risk $=\sum_{\mathrm{W}}($ Frequency $\otimes \underbrace{\text { Severity }}_{\text {Intensity } \otimes \text { Damages } \otimes \text { Value }})$

The dependability analysis context (Zwingelstein 1995) is used to analyse technological systems such as protection works failures. It introduces the concept of detectability: the criticality (instead of risk) of a system failure is assessed according to its frequency, severity as well as the possibility of early detection (Eq. 7).

Risk $=\sum_{\mathrm{W}}($ Frequency $\otimes$ Severity $\otimes$ Detectability $)$

Risk reduction measures and strategies (Fig. 2) can be suggested: mitigation actions are based on non-structural 
Fig. 2 Structural and nonstructural risk reduction measures

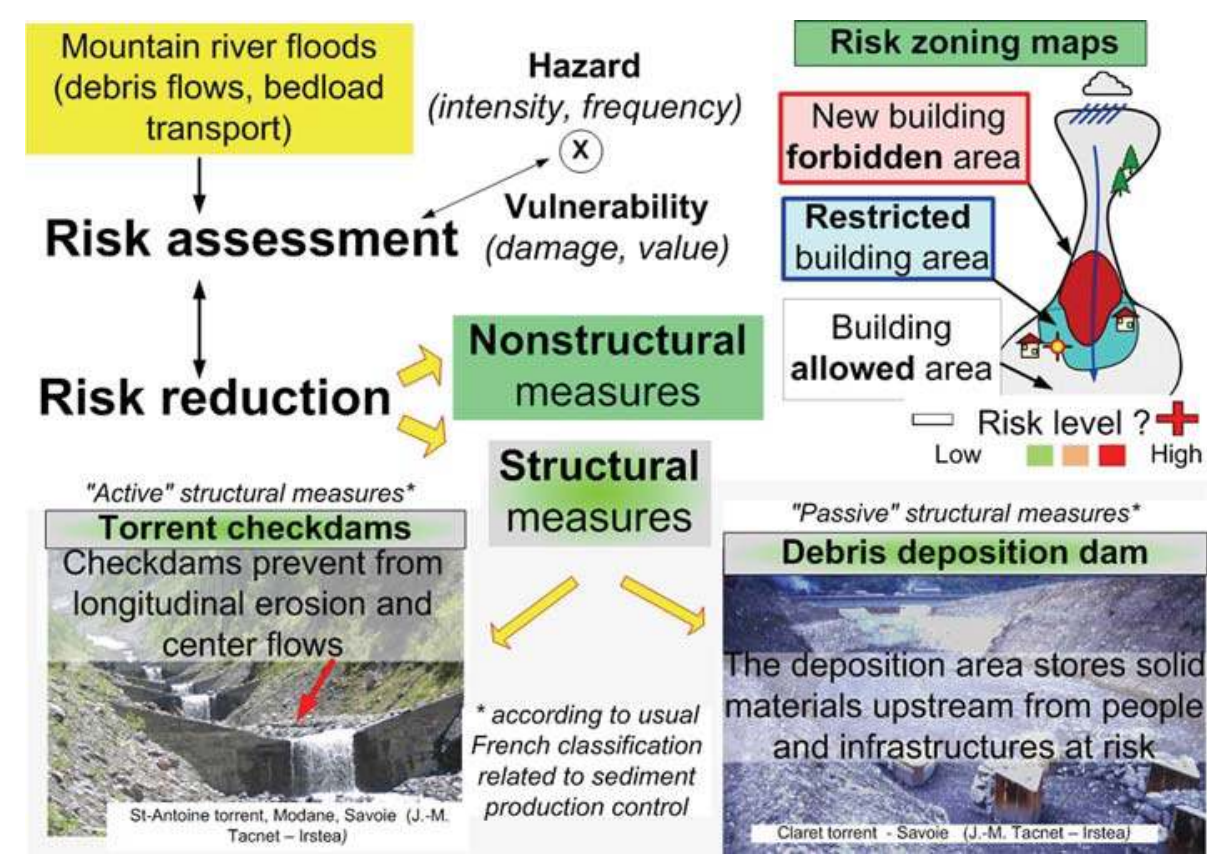

measures such as land-use control through risk zoning maps (MATE and METL 1997), preventive information and structural measures such as civil engineering protection works (checkdams, snow nets ). Risk managers, local authorities and infrastructure managers therefore must choose to implement a combination of these structural and non-structural measures (Fig. 1).

Making the best decision in the event of rapid mass movements in mountain areas encounters problems in the assessment and management process because of the lack of information and knowledge on natural phenomena and the heterogeneity and reliability of the information sources available (historical data, field measurements and expert assessments). Decisions are therefore often based on imperfect information (uncertain, imprecise, incomplete, conflicting) provided by multiple and heterogeneous sources (numerical models, expert assessments, Geographic Information Systems (G.I.S) or historical databases etc.).

For example, in the context of risk zoning and mapping, the goal was to determine zones where buildings are either allowed, restricted or forbidden. The snow avalanche risk level assessment requires using several types of information, including phenomenon triggering, propagation factors that are sometimes difficult to assess precisely and provided by more or less reliable sources (Tacnet et al. 2010b).

One major goal today is therefore to assist decisionmaking, while considering the availability, quality and reliability of information content and sources. Traceability and transparency of the expertise process are the core objectives of our approach. This paper focuses on the principles of an integrated risk management methodology considering and propagating all types of information imperfection in the reasoning process. Due to space restrictions, it does not detail the numerous methods used and specifically designed to help solve the problem. Therefore, we emphasise how the real-case context and modelling the problem are related and the problems encountered for each of the different methods presented. This paper is organised as follows. The introduction comprises this first section followed by Sect. 2 which reviews the principles and concepts of natural risks management in mountain areas. It explains the overall needs for traceability and describes the nature and reality of information imperfection. Section 3 sketches the integrated methodology implemented to identify the decision contexts, to consider information imperfection in multi-criteria decision-making methods, to propagate uncertainty in numerical modelling and to capitalise all these techniques and approaches in information systems. Section 4 is a discussion and conclusion describing the main inputs of the methodology and perspectives.

\section{Background and needs in expert assessments}

2.1 Needs for decision-aiding methods and traceability for natural risk management processes in mountain areas

Risk management is a complex decision process related to several temporal steps (crisis management, recovery, prevention and preparation) (Fig. 3) and to different 
Fig. 3 Expert assessments are required at every stages of the risk management process
Fig. 4 Experts play different roles during all the risk management stages and collaborate closely in decisionmaking
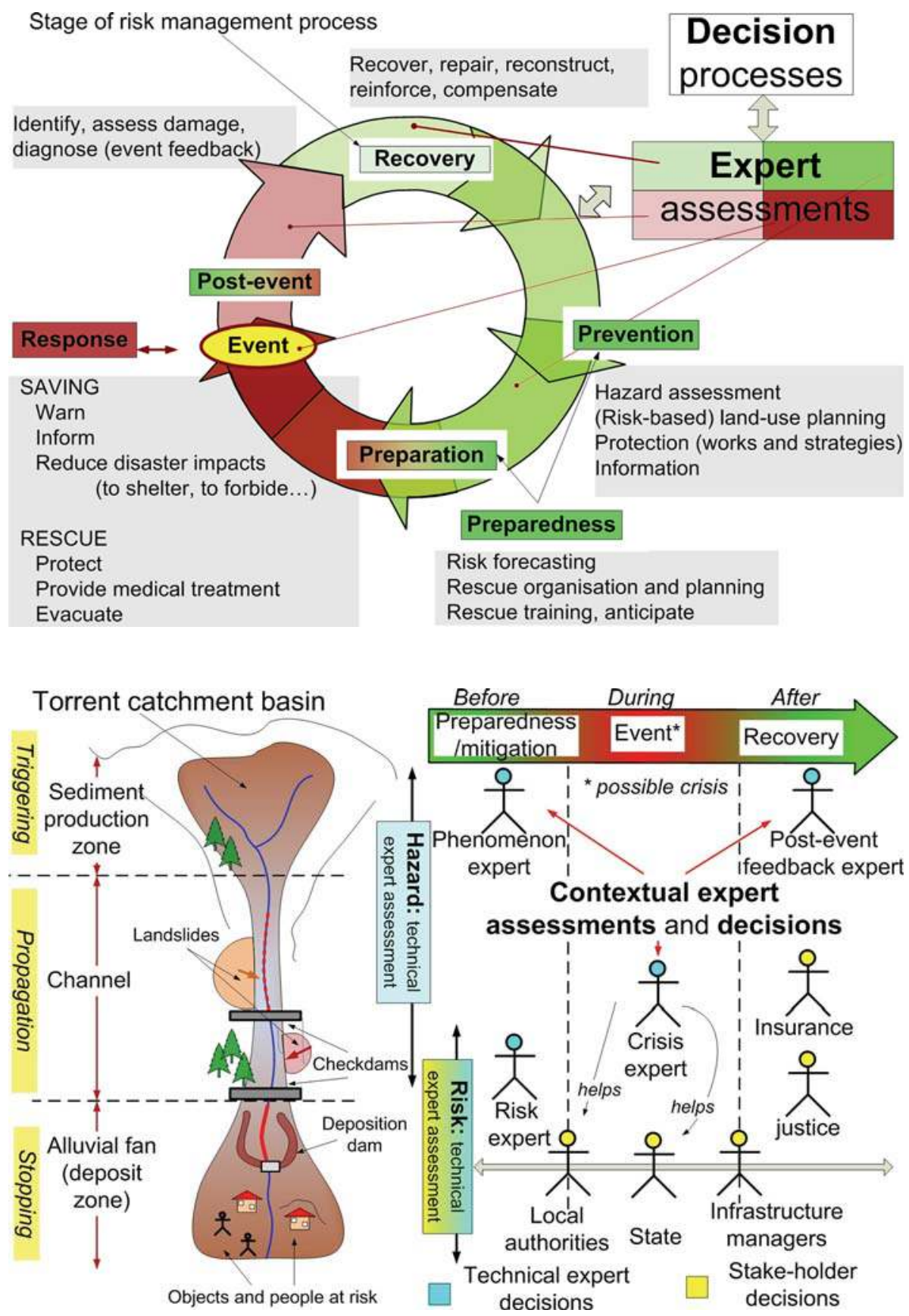

geographical areas (triggering, propagation and stopping zones) (Fig. 4). Decisions often result from a combination of several expert assessments with possibly contradicting or conflicting positions (Woo 1999; Tacnet 2009).

During all these periods, experts are involved in hazard, vulnerability and risk assessment. The same expert may contribute to various types of expert assessments depending on the temporal step of the risk management process, and the question that has been put to him about the description of a phenomenon, a hazard or risk level assessment or the design of suitable protection works. The contribution may range from the design of prevention measures to involvement in legal procedures (Fig. 4) (Tacnet and Lacroix 2005).

Traceability is expected from users and decision-makers. In natural risks management, final decisions depend on raw data quality (or imperfection) and sources reliability (Fig. 5). The relation between all these steps from data collection to decisions (Fig. 5), including information imperfection must be described. The goal and challenge are to develop methods that can represent, treat and capitalise information quality in a reasoning process. 

from data acquisition to risk management decisions
Fig. 5 Imperfection propagates

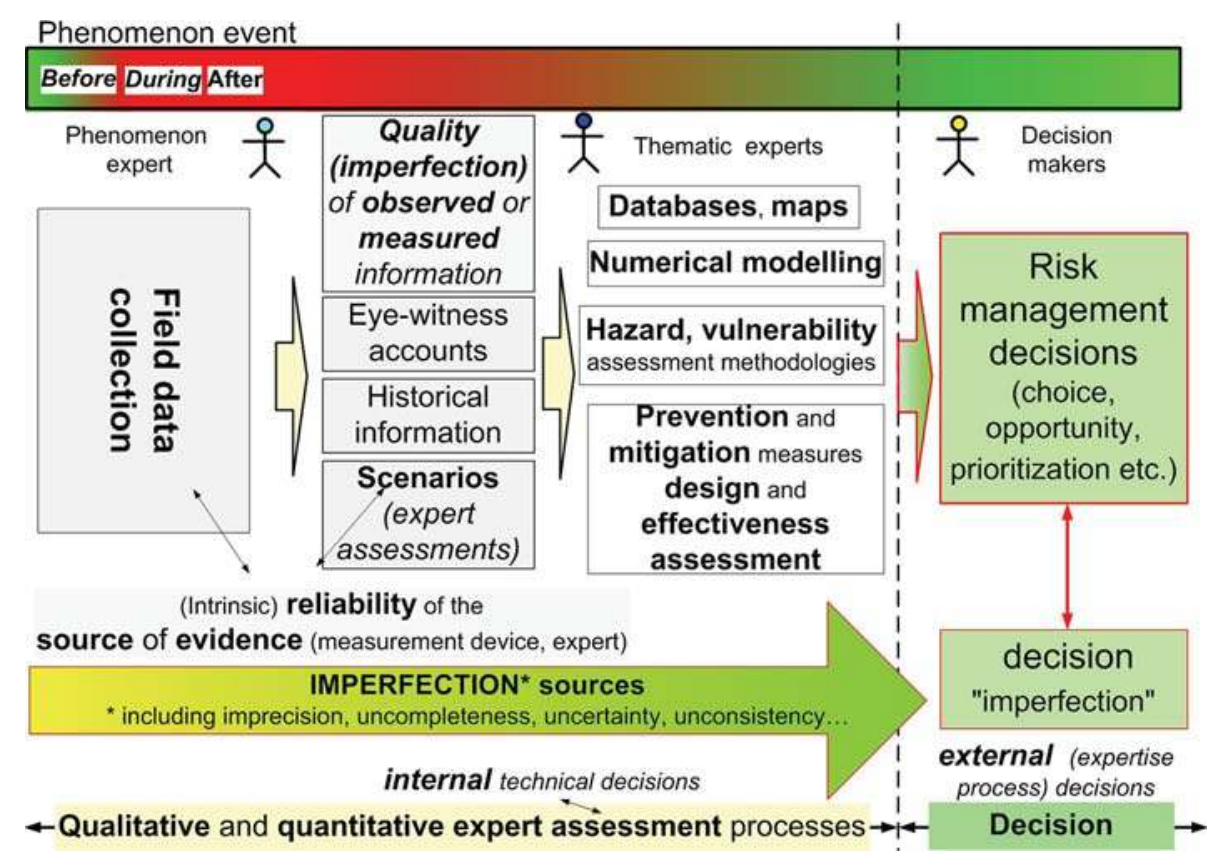

Fig. 6 Indicative criteria used by magistrates for expertise quality assessment (Tacnet and Lacroix 2005)

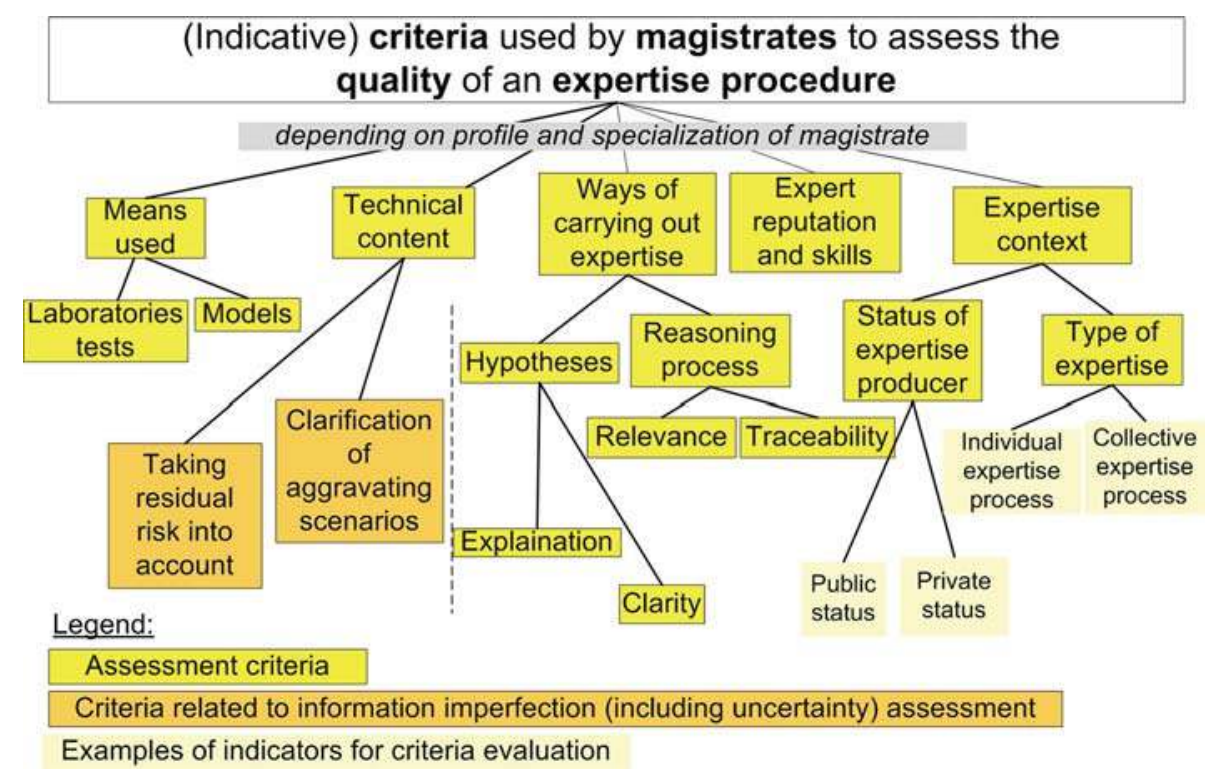

Traceability, which describes the data flow across the different reasoning processes, expert assessments and tools, appears as a main requirement in decision-making processes. For example, this traceability is required in standards related to expert process procedure description at the national level (AFNOR 2003) as well as in an international context (ISO 2009).

Moreover, expectations are not limited to technical assessment and engineering-related decisions. In recovery steps, when damages and injuries have occurred, magistrates are called to analyse the nature and quality of the expertise procedure. Traceability as well as uncertainty, aggravating possible scenarios are then considered as essential and expected features of the expert assessments (Tacnet and Lacroix 2005). Information imperfection elicitation and the detailed description of any reasoning processes are the main criteria considered by magistrates (Fig. 6).

\subsection{A dual decision-making context}

Technical decisions, mainly related to risk analysis, are only one part of the results expected from an integrated risk management process. The integrated risk management 
Fig. 7 Definition and relations within the risk concept, adapted from Amman (2006)

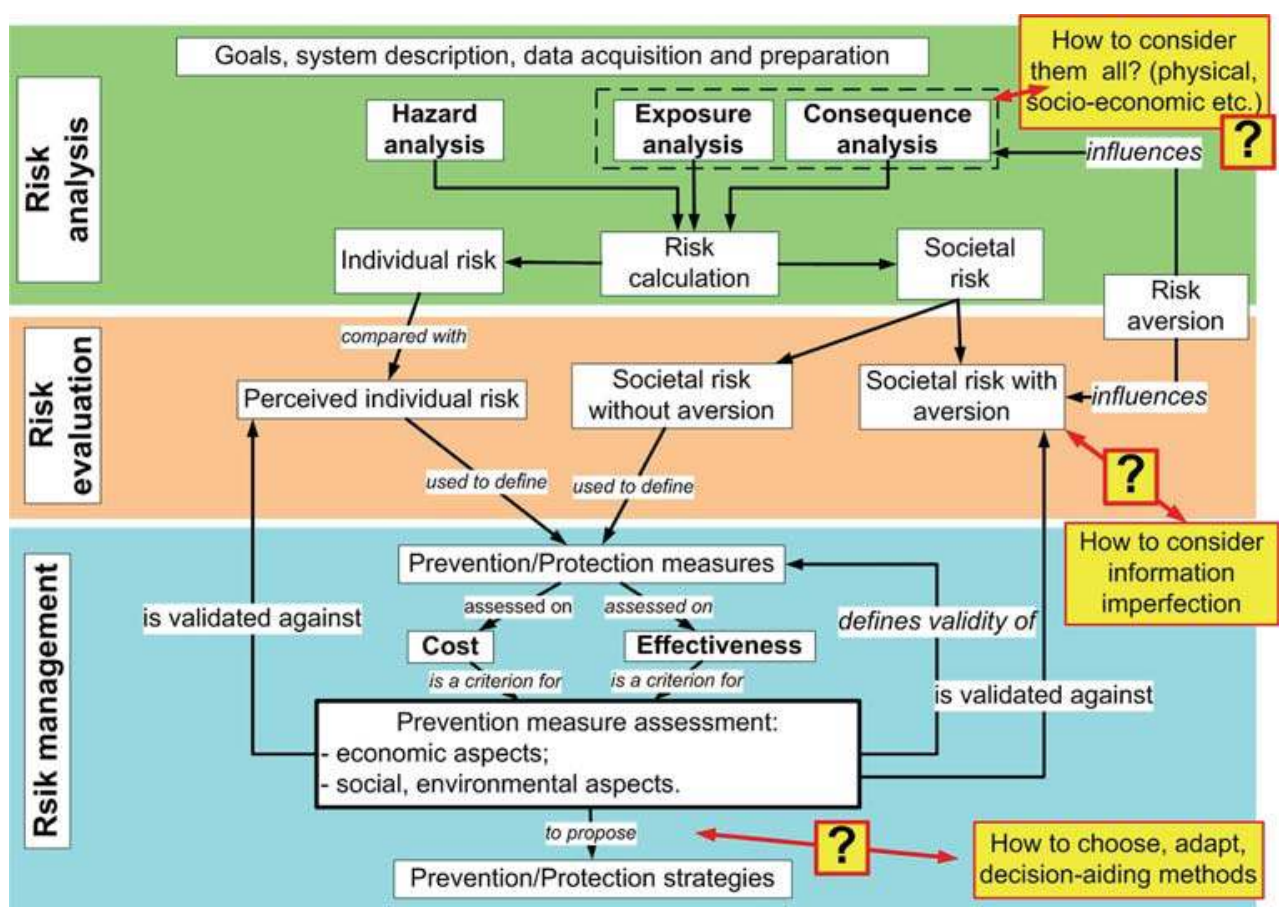

Fig. 8 Expert assessments are only one part of the global decision context, adapted from Renn and Graham (2006)

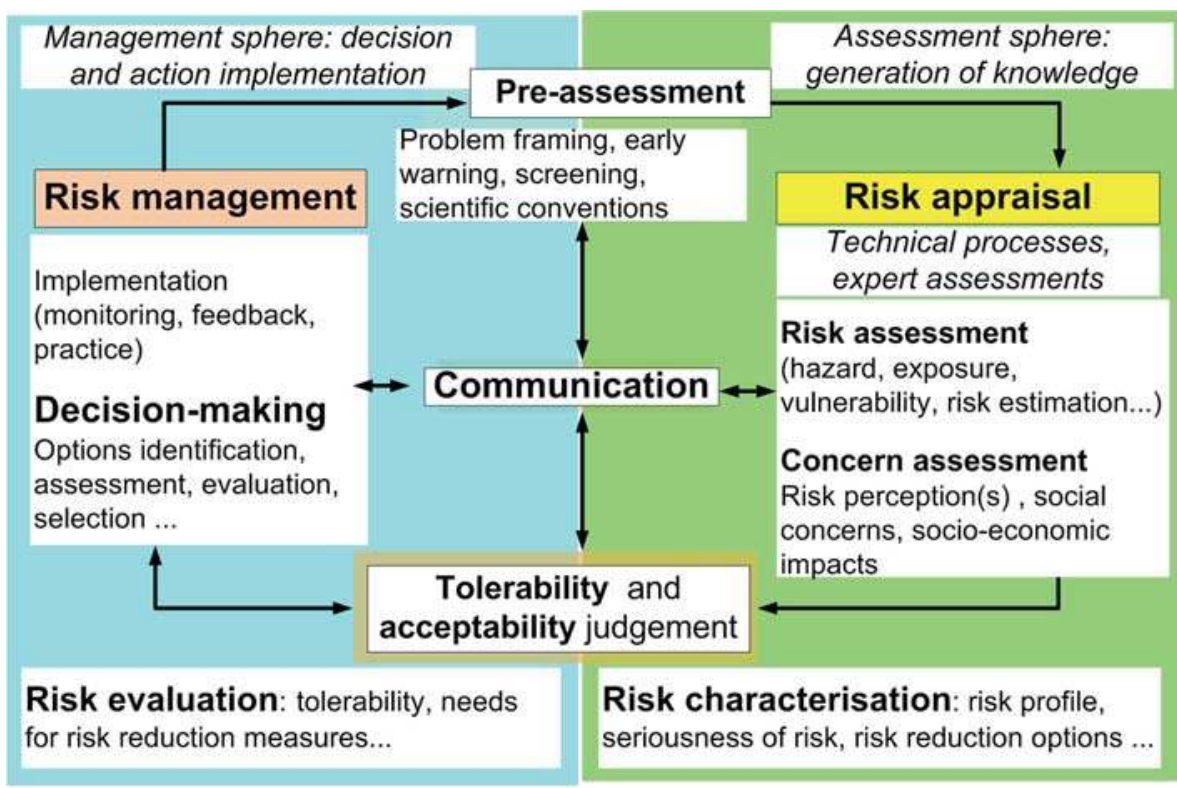

adapted from IRGC (International Risk Governance Council) framework is an extension of the classical risk analysis traditionally based on a sequential assessment of hazard, vulnerability and finally risk. This concept introduces several types of feedback between technical assessments and evaluation by the decision-makers (Fig. 7).

A clear difference must be made between two different contexts corresponding to both the technical and management sides of decision-making corresponding to risk appraisal (or analysis) and risk management, respectively, which introduces social evaluations and choices to technical decisions (Figs. 7, 8). Developing ad hoc decision-aid methods therefore require therefore first describing the specific decision contexts and decision levels.

In this context, the expert reasoning process itself can therefore be considered as a partial decision process within a more global decision framework. These expert assessments can be considered as decisions (Merad et al. 2012) based on imperfect information provided by more or less reliable sources (Tacnet 2009). 
2.3 Using ad hoc theoretical frameworks to represent and process information imperfection

Any decision is closely related to information availability, type, content and imperfection (or quality) (Dubois and Prade 2006). Figure 9 summarises these information features and describes in greater detail the four categories of information imperfection selected. Information can be objective (based on observed facts or measurements) or subjective (based on human opinion or interpretation). Its content can be either quantitatively measured by numbers (e.g. numerical value corresponding to a physical variable) or qualitative with reference to categories ("low", "medium" etc.). The term "imperfection" is used instead of "uncertainty", often used in common language and sometimes ambiguous in an attempt to differentiate between the main types that we have extracted from the numerous existing taxonomies. ${ }^{1}$ Inconsistency relates to the concept of conflict between sources (e.g. two experts argue about how much snow might be accumulated by an avalanche, about the possible paths of a debris flow on the alluvial fan ). Imprecision corresponds to cases where information is insufficient. This occurs when numerical values are insufficiently known (e.g. "the volume of a debris flows will be between 10,000 and $30,000 \mathrm{~m}^{3}$ ") or when natural language is used to provide a vague description of the system (e.g. "the snow deposit height will be 'high' "). Incompleteness represents a lack or partial availability of information (e.g. "a flood event has happened on the 3rd of July, 1987", but no information exists on its volume). Uncertainty relates to the relation between the real state of a situation and the assessment of this situation (Helton 1997). It includes aleatory uncertainty (also called irreducible, type A, stochastic, objective uncertainty or variability) and epistemic uncertainty, which results from a lack of knowledge of the system (also called subjective, type $B$, reducible, knowledge uncertainty or ignorance). It is sometimes possible to reduce this epistemic uncertainty by additional information in case of a priori uncertainty (e.g. additional measurements could improve knowledge of a potential landslide), while this is impossible when information (and related uncertainty) is $s u b$ jective by nature (e.g. the probability of a meteor crash in the next 10 years). Epistemic uncertainty can also derive from information source reliability because the source is not self-confident or because it may introduce errors (e.g. "I think that the avalanche reached this point").

These different types of imperfection are not exclusive: one can be certain about imprecise information, uncertain about precise information etc. To represent and combine all these types of imperfect information and their possible

\footnotetext{
${ }^{1}$ See Parsons (2001) for a complete review.
}

combinations to take decisions for risk management, theoretical frameworks and specific integrated methodologies are needed. Probability theory is obviously widely used in the natural hazards context to represent uncertainty, but somewhere fails to handle vague, imprecise, uncertain and conflicting information correctly. In the context of natural risks, different kinds of imperfection are encountered and this requires seeking other alternatives to this classical theoretical framework (see also Sect. 3.2). We therefore review the theories that have been proposed to represent the main types of information imperfection selected above.

Fuzzy sets theory (Zadeh 1965) represents vague information and relates to an imprecise quantitative evaluation. Fuzzy numbers are used to link quantitative values and linguistic variables (Fig. 10).

Possibility theory (Zadeh 1978; Dubois and Prade 1988) represents both imprecision and uncertainty using possibility distribution. Instead of a single discrete evaluation, several consonant intervals with increasing confidence levels can be chosen: the wider the interval is, the more confident the expert is in his evaluation of the criterion. On the figure (Fig. 11), the source (an expert) provides an imprecise and uncertain evaluation of the number of winter occupants in a given area. He is only able to propose intervals with confidence level: the expert has a $75 \%$ level of confidence that the number of occupants $x$ will be in the interval $[8,15]$, he is certain that the number $x$ will be in the interval $[6,20]$. This representation is used both in advanced multi-criteria decision-making and in the hybrid sensitivity approach (see Sect. 3.2) and advanced multicriteria decision analysis methods (see Sect. 3.3).

Evidence or belief function theory (BFT) offers a powerful mathematical formalism (belief functions) to model our belief and uncertainty on the possible solutions of a given problem. It allows one to both represent the imprecision, uncertainty, conflict and ignorance of information and to fuse information provided by more or less reliable sources. Information fusion consists in merging information stemming from several sources to answer questions or more generally to make decisions (Bloch et al. 2001).

Evidence or belief function theory allows one to represent and fuse information evaluation provided by more or less reliable and conflicting sources based on the same hypotheses of a set called the frame of discernment, denoted as $\Theta=\left\{\theta_{1}, \theta_{2}, \ldots, \theta_{n}\right\}$. Each source $s$ (e.g. an expert) defines basic belief assignments (bba's) denoted $m_{s}($.$) . The hypotheses must be exhaustive and exclusive in$ the Dempster-Shafer (DST) framework (Shafer 1976), while Dezert-Smarandache theory (DSmT) relaxes this hypothesis and provides a versatile framework to represent imprecise as well as vague concepts (Fig. 12). One of the pillars of DST is Dempster-Shafer rule (DS) for combining belief functions. The purpose of the development of 
Fig. 9 Uncertainty is a specific type of information imperfection (Tacnet 2009), adapted from Parsons (2001)

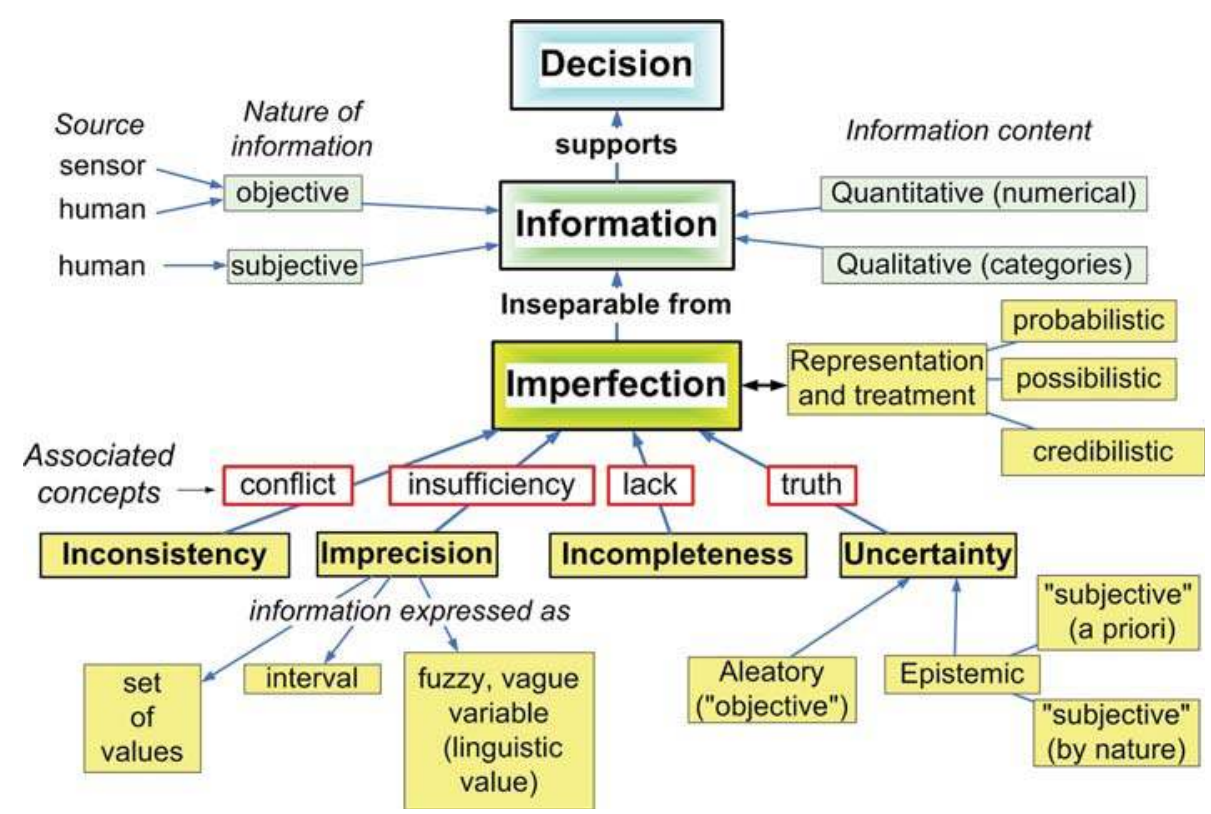

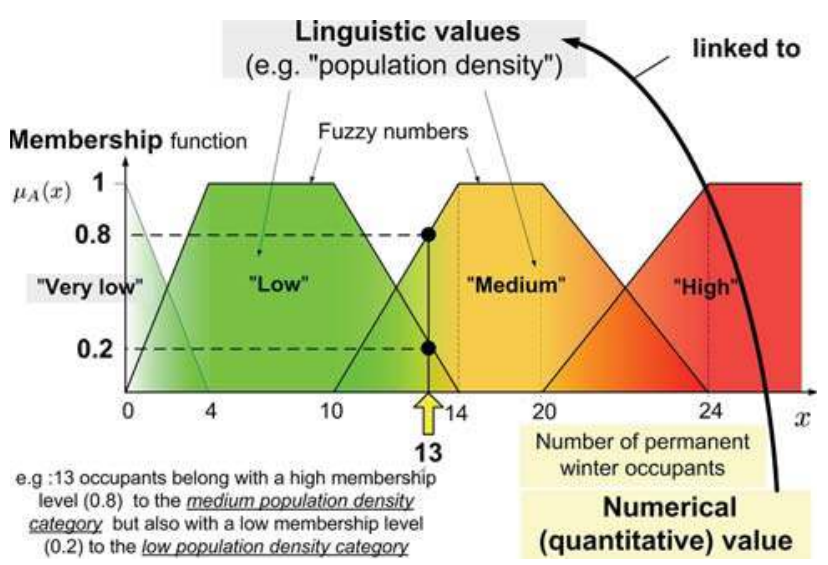

Fig. 10 Fuzzy numbers can be used to represent expert knowledge

Dezert-Smarandache theory (DSmT) (Smarandache and Dezert 2004-2009) ${ }^{2}$ is to overcome the limitations of DST by proposing new underlying models for the frames of discernment in order to fit the nature of actual problems better, as well as new combination and conditioning rules for circumventing problems with the DS rule, most particularly when the sources to combine are highly conflicting.

Sources can be discounted with regard to their reliability, which fits our decision context perfectly. Specific discounting methods have recently been proposed to consider importance and reliability in the context of multi-criteria decision-making (Smarandache et al. 2010; Dezert et al. 2010; Tacnet 2009). The classical concept of expected utility, used in decision theory, has been adapted within the

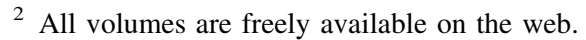

evidential reasoning framework, using either a subjective/ pignistic measure called $\operatorname{Bet} P\{$.$\} (usually adopted in the$ DST framework) or $\operatorname{DSmP(.)}$ (as suggested in the DSmT framework) as the probability function needed to compute expectations. Usually, the maximum of the pignistic probability is used as the decision criterion. The maximum of $\operatorname{Bet} P\{$.$\} is often considered as a balanced strategy$ between the two measurements provided by theory for decision-making: the maximum plausibility (optimistic strategy) or the maximum credibility (pessimistic strategy) (see Tacnet and Dezert 2012).

Finally, the risk management process can be considered as a decision process largely based on heterogeneous and imperfect information provided by several more or less reliable sources such as expert assessments and numerical modelling etc. Combining all types of information, taking into account the reliability of the sources, evaluating and propagating the quality of information are not part of classical approaches for natural risk management. The following developments propose an integrated approach that combines new uncertainty theories, decision-aid techniques, numerical modelling and GIS related to the stages of risk management.

\section{An integrated approach}

New methods and different way of thinking natural risk assessment are a complex framework that combines several actors, different types of information and sources. New decision-making aid methods are a way to help decisionmaking and to improve traceability since they formalise data as well as reasoning principles and processes. The key 
Fig. 11 Possibility distributions are an easily understood framework to represent imprecision and uncertainty
Fig. 12 Basics of DempsterShafer theory (Shafer 1976) and Dezert-Smarandache theory (Smarandache and Dezert 2004-2009)
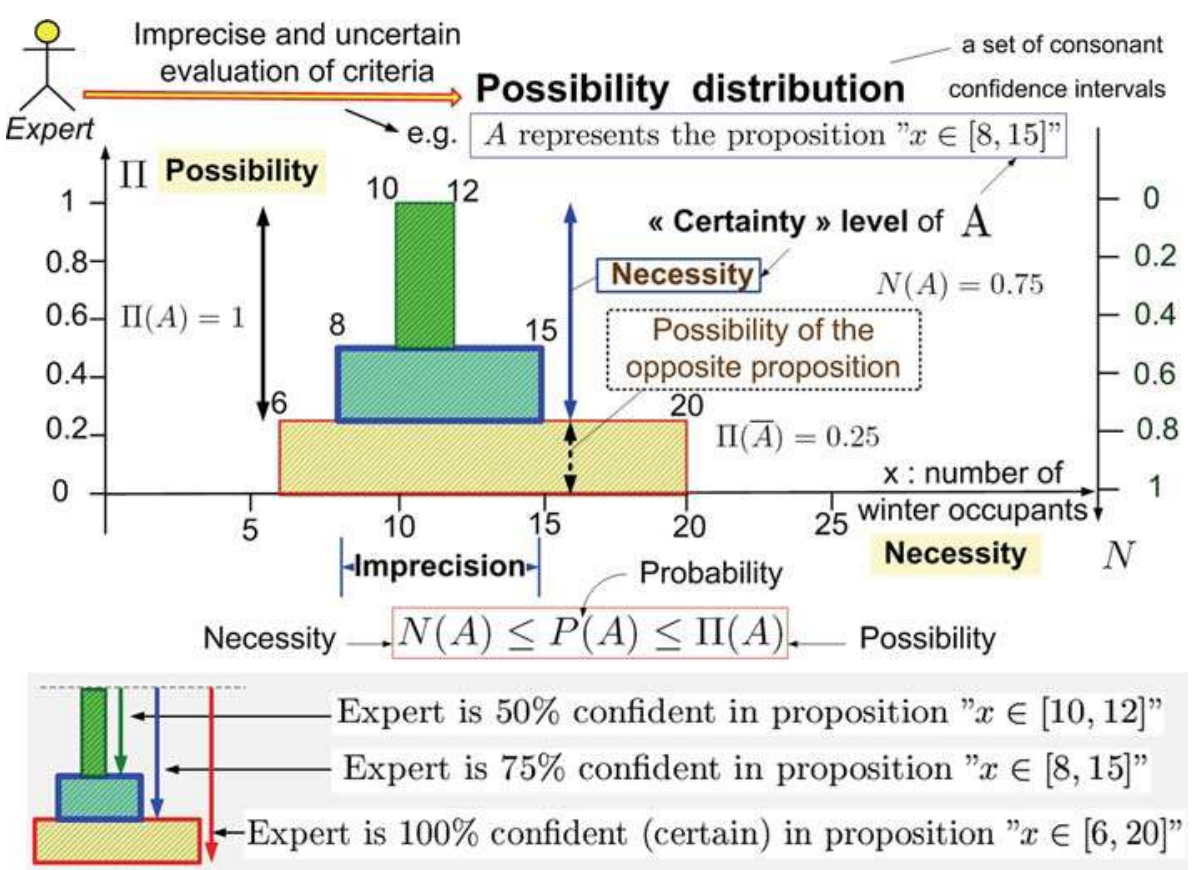

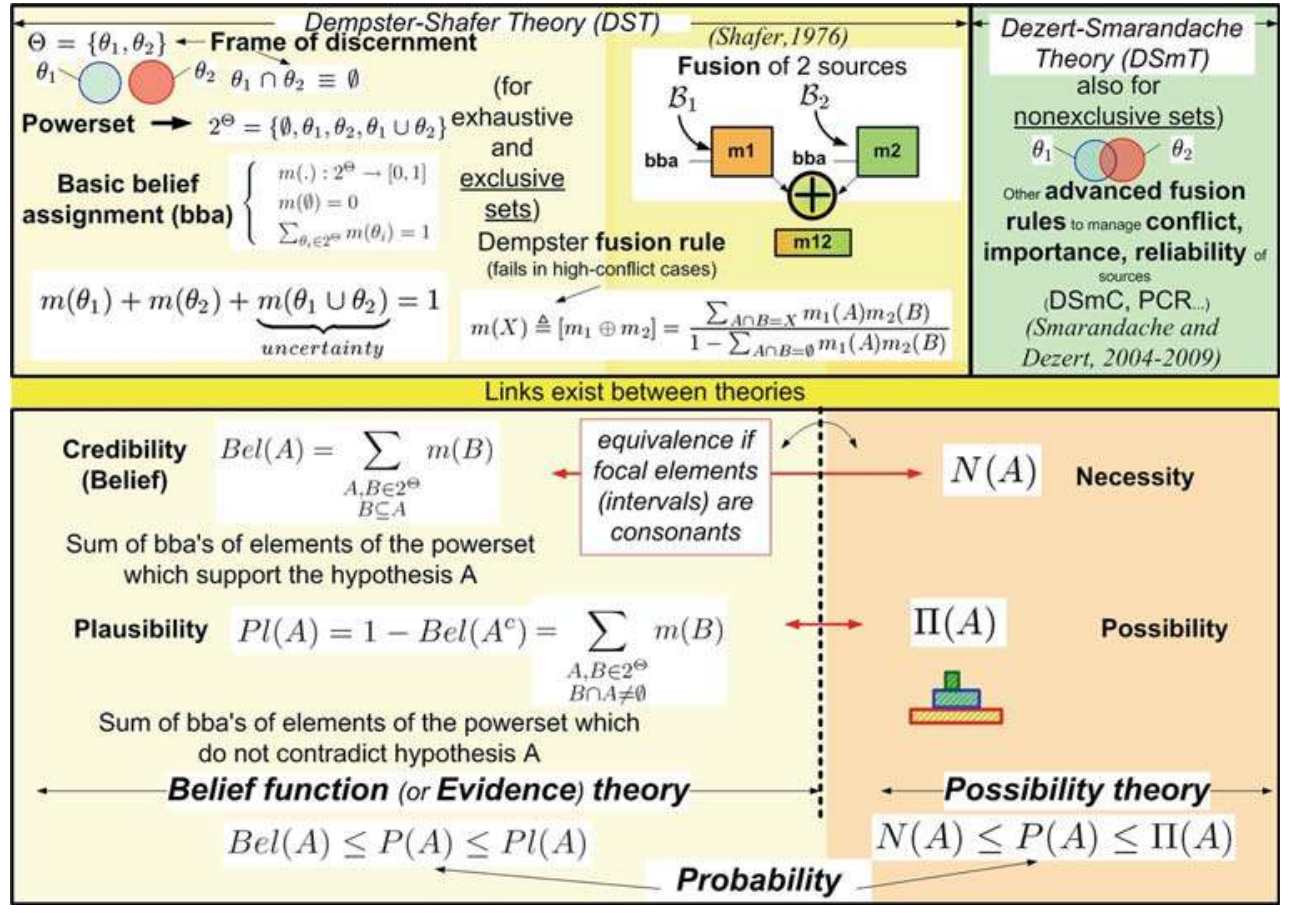

question is not only to obtain a result, but also to explain how it was obtained (assumptions and information imperfection) in an objective and transparent way.

The development of an integrated risk management process in contexts of imperfect information such as mountain risks implies adapting these methodologies and modelling the problem so that it complies with these theoretical frameworks. Description of the decision context is the first obvious although trivial step in decision support systems design. A combination of techniques ranging from information imperfection representation to imperfection propagation in numerical modelling is necessary but requires adaptations. Information fusion and uncertainty theories are used to gather information: fuzzy sets, possibility and belief function theories are able to consider all types of information imperfections such as vagueness, 


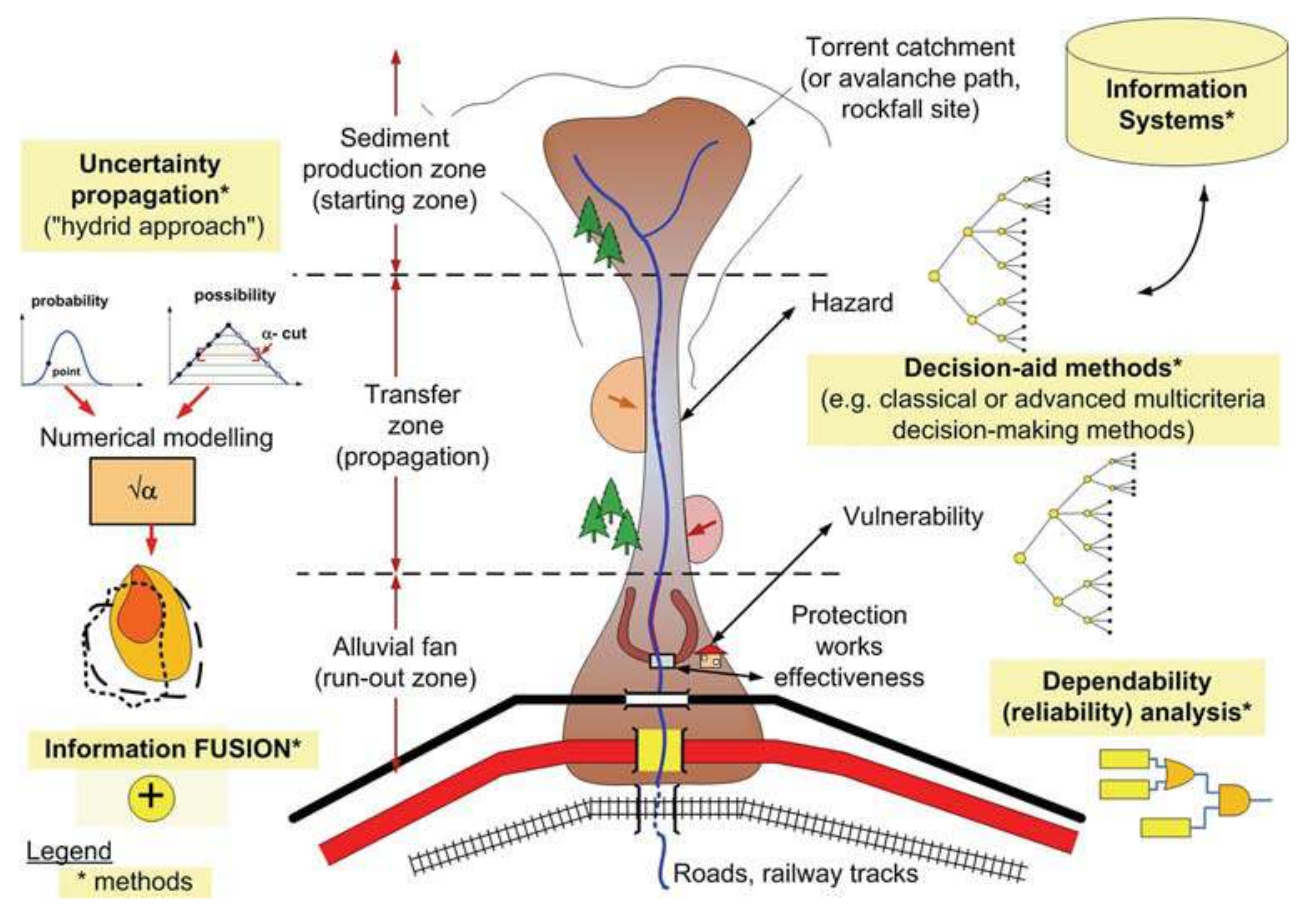

Fig. 13 Methods must be combined in integrated risk management

imprecision, conflict and uncertainty. When needed, they supplement the classical probability theory. This section describes how different theoretical and technical frameworks are combined to contribute to risk assessment in a context of imperfect information. The selected topics, part of a global and integrated methodology presented below, cover:

- elicitation of decision contexts (Sect. 3.1);

- propagation of information imperfection in numerical modelling (Sect. 3.2);

- development of advanced multi-criteria decision-making methods (Sect. 3.3);

- consideration of geographical features of decisions in a context of information imperfection (Sect. 3.4);

- capitalisation and traceability of reasoning processes in information systems frameworks (Sect. 3.5);

- application to a specific decision problem related to protective structure effectiveness using dependability analysis (Sect. 3.6).

Integration consists in using all these approaches for technical decisions related to the expertise process (Fig. 13).

In the context of natural risks in mountainous areas (snow avalanches, rock-falls, debris flows), this framework follows the thematic approaches from triggering to interaction with the objects and people at risk. Risk assessment (Eq. 2) involves first identifying the phenomenon and the triggering conditions (in the starting zone), secondly analysing its propagation (a mountain stream channel, an avalanche path etc.) and finally its effects on people, infrastructures and buildings located in the run-out zone. Following the physics of the phenomenon from the top to the bottom of the risk basin, several methods can be used. A multi-criteria decision-making method is used to assess the overall sensitivity of a given site (e.g. avalanche triggering, sediment production potential). Numerical modelling is used to analyse the phenomenon's propagation. Economic approaches are used to assess risk and protection strategy effectiveness. Dependability analysis is used to assess protection works' structural and functional effectiveness. The results of all these stages depend on information quality (or imperfection), which propagates from one step to another. The principle is therefore to assess this imperfection on raw data and processed data in order to propose an additional information quality layer for each part of the risk basin (Fig. 14). Risk maps corresponding to the run-out zone are based on several (imperfect) information sources related to vulnerability and hazard assessment. A fusion process (see Sect. 3.4) is proposed to combine imprecision, uncertainty and finally determine a spatialised quality index for decision-making: thus, the decision-maker has additional information on the confidence that he can give to the result of combined expert assessments and decision-aid methods. This information quality layer contributes to supplementing the classical technical frameworks with an information quality layer. In hybrid numerical modelling (see Sect. 3.2), ranges of 
Fig. 14 Information quality and traceability of the decisions associated with risk management

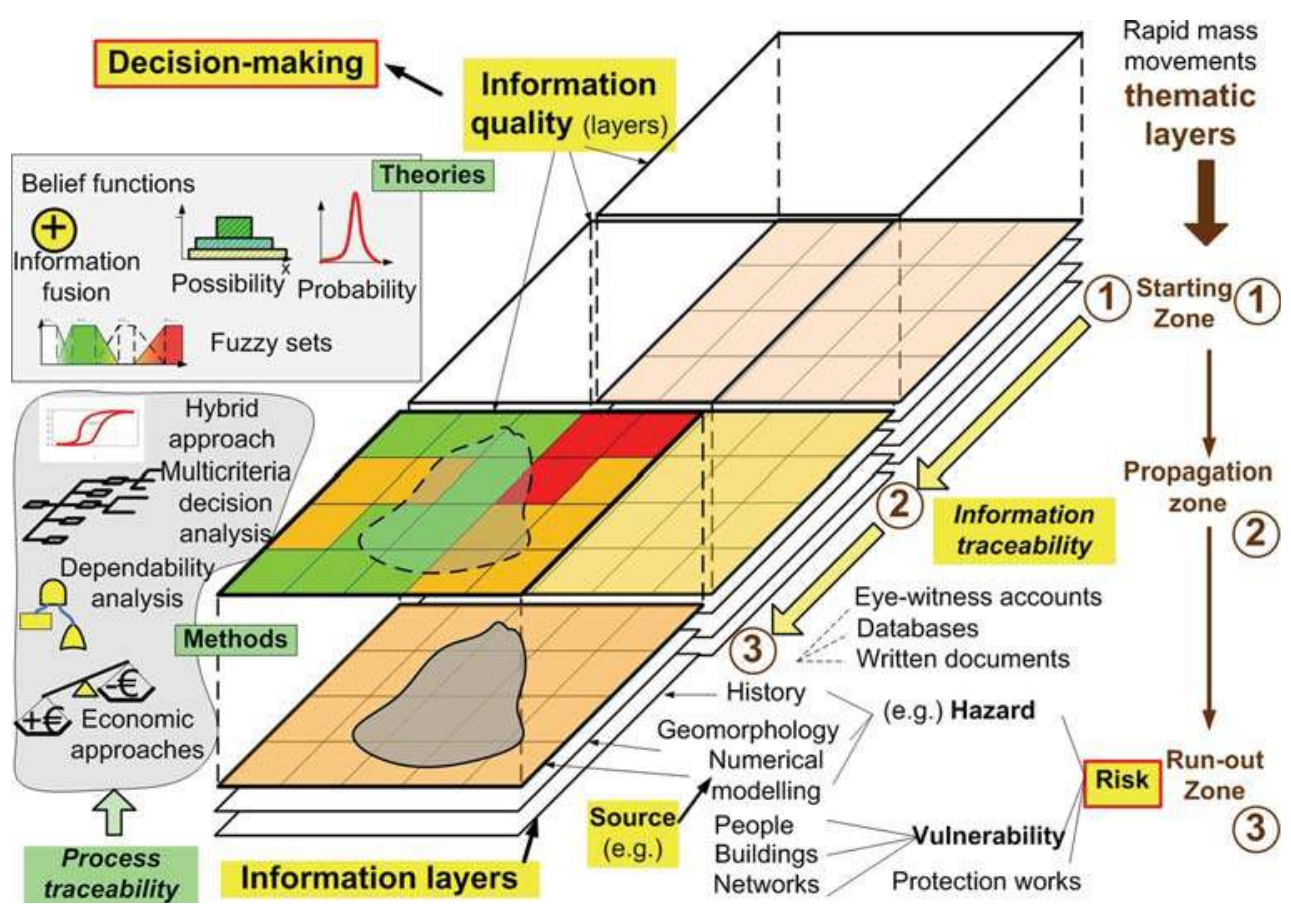

intervals of probability results can be interpreted as a quality index (Fig. 18).

\subsection{Description of decision contexts}

The formulation of a decision support problem is expected to result from co-construction (Roy 1985) with decisionmakers (experts, technical managers, public bodies, economic actors, citizens etc.) providing, in such conditions, a space for possible discussion and negotiation. To a certain extent, the design process can be considered here as important as the decision support system itself. Classical natural risk assessment is a physically oriented approach mainly based on hazard assessment. It implicitly assumes that technical results are the imperative basis of all decisions. In this context, methods and models are considered directly as decision-making tools. Although they remain essential to the whole process, it is an illusion to think that they are sufficient. Moving from technical approaches to actual complex decisions (Fig. 4) requires to develop specific methodologies and us ad hoc tools to identify precisely the decision contexts and propose decisionmaking methods fitting to the users requirements and natural risks context specificity. Multi-criteria decision-making methods are adequate to cope with difficult and complex decision contexts (Figueira et al. 2005). The global methodology is based on the identification of actors, solutions, criteria, preferences and evaluation of results (Fig. 15).

However, in practice, implementing this methodology is not obvious. We present here an example dealing with risks in the context of rail and/or road infrastructures and corresponding to the choice of risk management strategies (Fig. 1). These strategies correspond either to active measures (building protective structures against natural hazards) or passive measures such as the development of rescue and alternative paths in case of rail or road closures (Tacnet 2012). For example, the main characteristics of a decision problem related to road risk management are described: decision-makers, motivations for a decision, the object of the decision (solutions, alternatives), the time schedule of the decision (real-time, mid-term, long-term decision) and the tools and methods used (Fig. 16).

\subsection{Possibilistic imperfection propagation in numerical modelling}

Numerical modelling results are essential data to assess hazard and evaluate the functional effectiveness of protection works such as dams and dikes. The issue is here to take information quality into account more faithfully in the global hazard assessment process. Sensitivity and uncertainty analysis of models are well-known problems (Saltelli et al. 2004). One propagates the known uncertainty concerning the input variables through the model, assessing the uncertainty of the output variables (Figs. 17, 31). In most usual uncertainty analysis approaches, the Monte Carlo sampling method is used through density function based on statistical samples and remains the most usual and successful theoretical framework to represent and propagate uncertainty.

In practice, when no data samples are available to support an objective probability distribution, experts propose 
Fig. 15 Methodology to design decision-aid systems

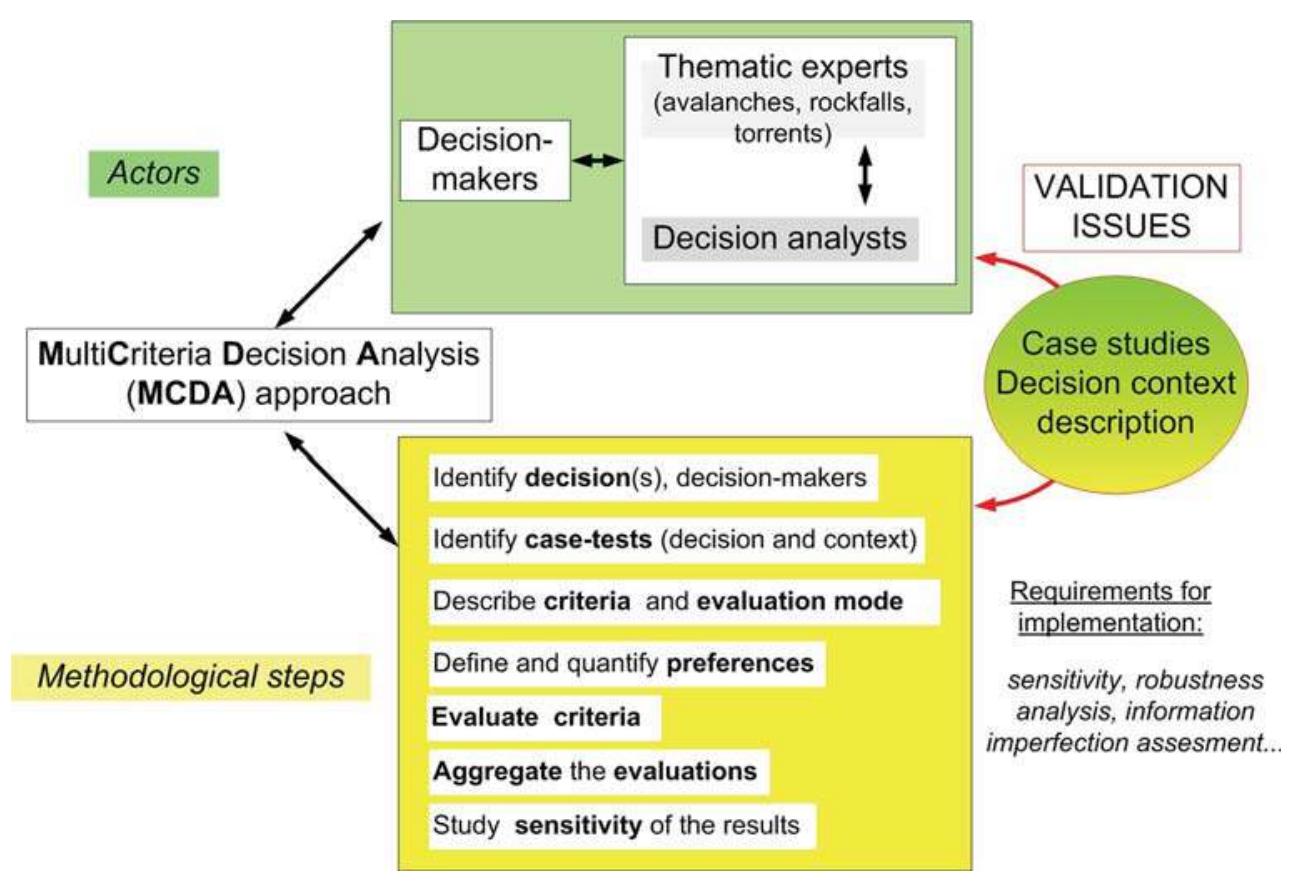

Fig. 16 Practical decision context identification for road risk management, adapted from Tacnet (2012)

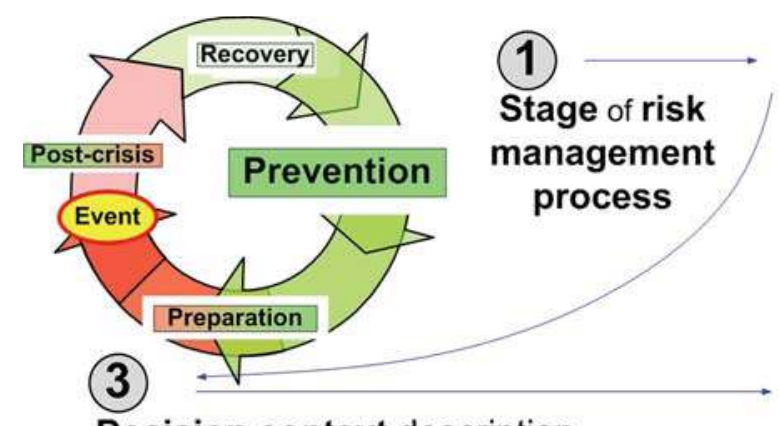

(2) Elicitation of decisions

Choice of road to protect Priorities for road protection Strategies for road protection Protection works effectiveness Decision context description

Actors Motivation Object " 5WH " Who decides? Why? What is decided? When? Where? How?

Time Spatial Real cases,
duration extent back-analysis

Which roads, infrastructures should we protect? How should we protect roads, infrastructures? Which roads, infrastructures should we protect first? Where, when should we maintain protection work first?
Choice and combination of Decision-aid methods

Multicriteria approaches Costs/Benefits-Efficiency Benefits/Opportunities/ Costs/Risks ...

\section{(5)} Validation an evaluation of inputs as a set of nested intervals with increasing levels of confidence. This can correspond to assertions resulting from expert assessment such as: "we are certain that this debris flow torrential flood has reached this point...", "it is possible that the volume will be between 20,000 and $25,000 \mathrm{~m}^{3} \ldots$... In this case, the choice of a probability density function would presuppose, in case of imprecise variables, that one adds some information and gambles on the real distribution. To consider the different aspects of information imperfection, especially its imprecision, the "hybrid" method (Baudrit et al. 2006, 2005; Chojnacki et al. 2009) of uncertainty analysis is used: the hybrid approach (Fig. 17) considers the real imperfection of information resulting from expert assessment. This methodology generalises, under some restrictive conditions, the usual Monte Carlo sampling method, using the theories described above: probability theory, possibility theory and belief function theory, used as practical tools for coding imprecise probabilities (Dubois et al. 2000). 
Fig. 17 Principles of uncertainty analysis: different theories can be used to represent information imperfection

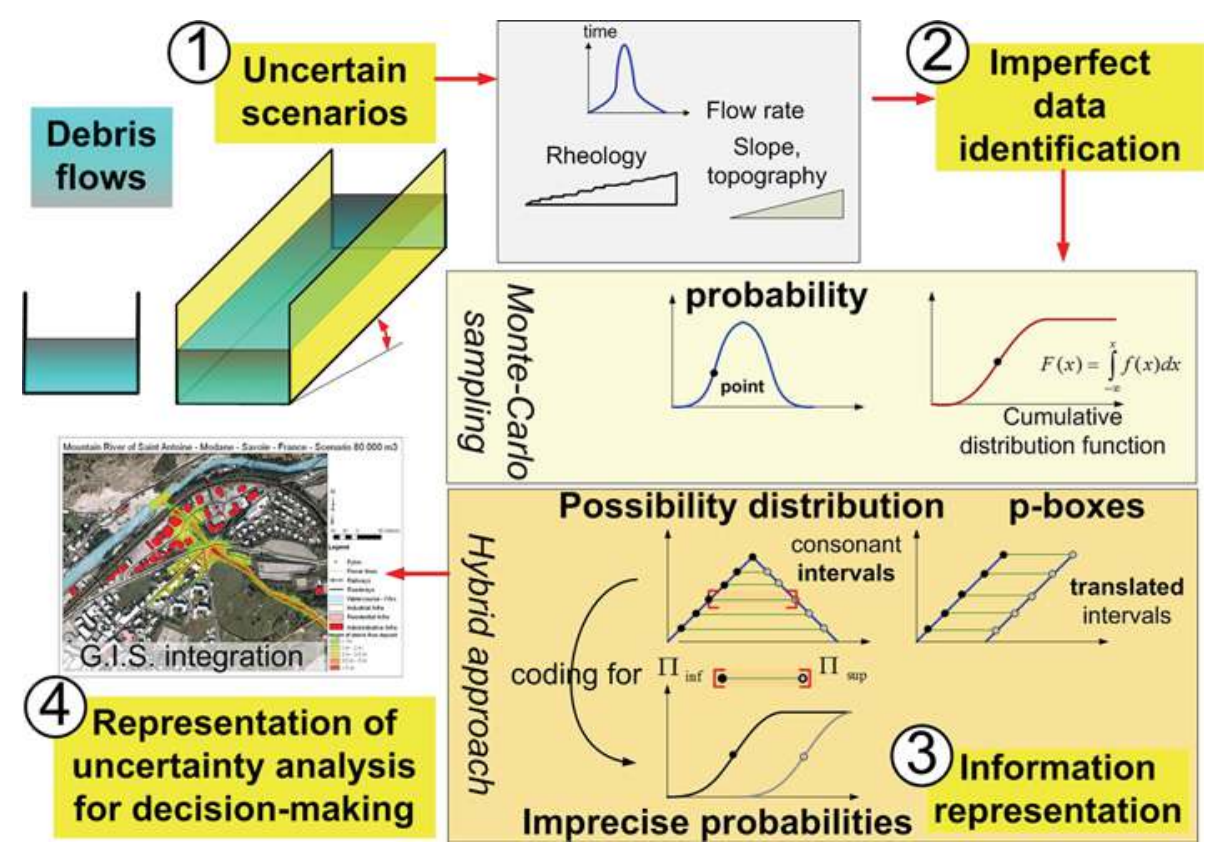

In the debris flows context, numerical models are used to assess height, speed and extent of flow. The lave2D model (Laigle et al. 2003) can model the extension of debris flow described by its rheological features, its input volume, the debris flows hydrograph and the local topography (Fig. 17). The hybrid approach has been used ${ }^{3}$ in the context of a torrent test bed (Dupouy et al. 2012) to propagate the different aspects of information imperfection, especially its imprecision (lack of information, measurement inaccuracy) in numerical modelling.

The results (quantile of deposition heights, threshold exceedance probabilities) show in each pixel (Fig. 18) the influence of data imperfection including those resulting from expert assessments on the simulation results and therefore provide a practical way to assess the information quality index.

The results correspond to intervals since input data were themselves imprecise: they comprise intervals of exceedance probabilities (e.g. the probability of obtaining a debris flow height higher than $2 \mathrm{~m}$ ) or the lower and upper bounds of a quantile (e.g. the height that is reached in $95 \%$ of cases). The results are less precise than Monte Carlo approaches using probability distributions values for input parameters, but they correspond to actual information available. The development and generalisation of such approaches remain important challenges for risk managers and decision-makers who may have to change their mind about the use and limitations of models. The results must be represented in a GIS to build maps. However, raw results of such approaches are not easily understood:

\footnotetext{
${ }^{3}$ Using the SUNSET software environment developed by IRSN.
}

intervals of probability can be transformed into an information quality index (Fig. 14) that will inform decisionmakers on the reality of information imperfection upon which they may base their decisions.

\subsection{Developing advanced multi-criteria decision- making methods}

Considering information imperfection in multi-criteria decision-making, multi-criteria decision-making methods (MCDM) have already been used in the context of natural hazards (Merad et al. 2004), but most methods are not designed to consider imprecision and uncertainty (Stewart 2005; Roy 1989). Several methods have been proposed to consider information imperfection, source reliability, importance and conflict, using the fuzzy sets as well as possibility and belief function theories. Implemented methods (Tacnet and Dezert 2012) consider information imperfection in total aggregation methods such as $\mathrm{AHP}^{4}$ (Saaty 1980) (see the ER-MCDA ${ }^{5}$ methodology in Tacnet (2009); Tacnet et al. (2010b)), partial aggregation methods such as the Electre outranking method (see Soft Electre Tri in Dezert and Tacnet 2012) or decisions in certain but also risky or uncertain contexts (see COWA-ER ${ }^{6}$ in Tacnet and Dezert (2011)). For example, the ER-MCDA methodology considers expert assessment as a multi-criteria decision process based on imperfect information provided by more or less heterogeneous, reliable and conflicting sources. This

\footnotetext{
${ }^{4}$ Analytic hierarchy process.

${ }^{5}$ Evidential reasoning-multi-criteria decision analysis.

${ }^{6}$ Cautious ordered weighted averaging-evidential reasoning.
} 

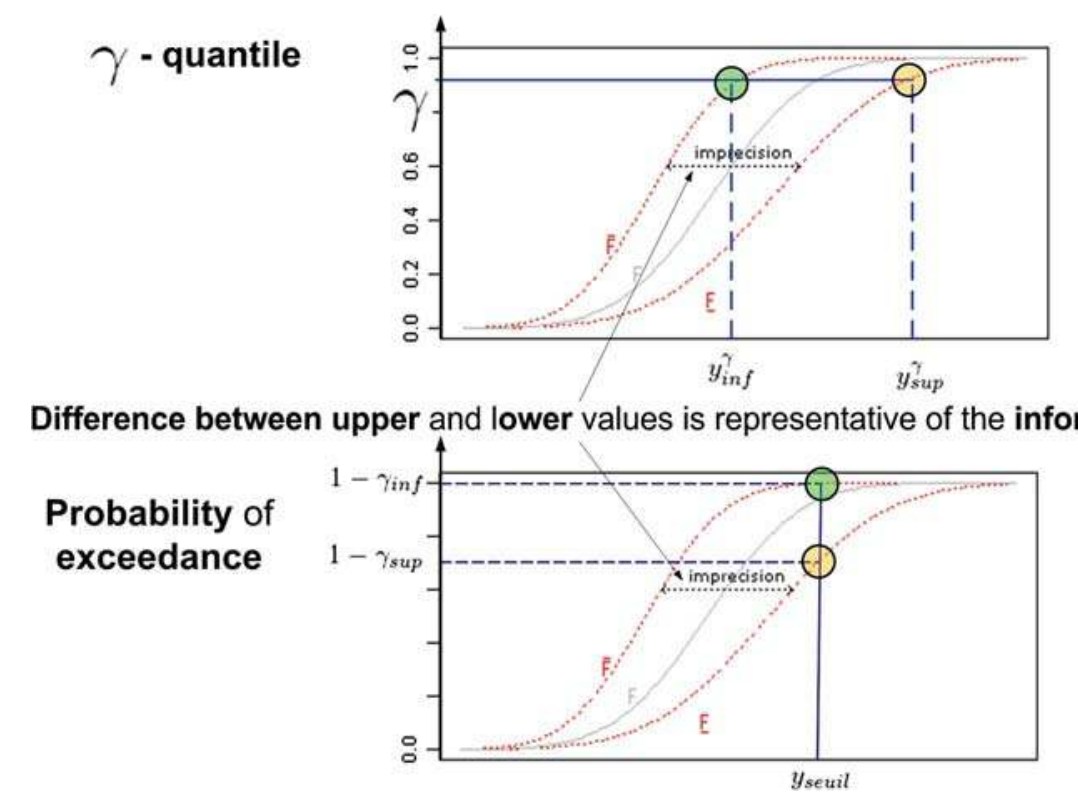

Fig. 18 Main criteria of interest used to interpret the results: quantile and probability of exceedance

methodology has been applied to risk sensitivity assessment problems.

Example of the ER-MCDA methodology, evidential reasoning and multi-criteria decision analysis (ER-MCDA) is a methodology combining the analytic hierarchy process (AHP) (Saaty 1980), a multi-criteria decision analysis (MCDA) method, fuzzy sets, possibility theory and information fusion using the belief function theory. Herein, we only describe the method's overall principle and its main advantages.

The first step consists in describing the decision-making problem including identifying qualitative and quantitative decision criteria (e.g. in Fig. 22, the sensitivity is assessed by vulnerability and hazard, vulnerability is assessed by number of occupants ). The decision hypotheses (e.g. low, medium and high sensitivity levels) are the components of the common frame of discernment $\left(\Theta=\left\{\mathrm{HD}_{1}, \mathrm{HD}_{2}, \mathrm{HD}_{3}, \mathrm{HD}_{4}\right\}\right)$ that are used for information fusion (Fig. 22). The classical AHP aggregation process is replaced by a fusion process. Each quantitative or qualitative evaluation of criteria has to be projected into bba's (basic belief assignment) ${ }^{7}$ corresponding to the frame of discernment.

Quantitative criteria are evaluated through possibility distributions representing both imprecision and uncertainty. A mapping model based on trapezoidal fuzzy intervals, denoted "L-R", links a criterion evaluation and the decision classes (low, medium, high). For each evaluation of a criterion by one source, each interval of the possibility distribution is mapped onto the so-called common frame of discernment of the decision according to surface ratios (Fig. 19).

\footnotetext{
$\overline{7 \text { See Fig. } 12}$.
}

These mapped bba's, denoted $m($.$) , are then fused to$ identify which hypothesis from the frame of discernment is finally chosen (Fig. 20).

At the end of the mapping process, all the criterion evaluations provided by each source are transformed into bba's according the common frame of discernment for the decision: these bba's are then fused into a two-step process. The classical AHP aggregation process is replaced by a fusion process (Fig. 21). The method has the major advantage of dissociating imperfect evaluation of criteria, combining several more or less reliable sources.

Starting from a classical hierarchy of criteria, the ERMCDA allows imperfect (imprecise and uncertain) evaluations of criteria by multiple more or less reliable sources (e.g. experts). These evaluations are fused together for each criterion. The results of fusion for each criterion are fused together to produce the decision profile (Fig. 22).

The method provides not only a single choice, but also proposes a "decision profile" that informs on the information quality level. The results provided by this method are, in our opinion, already quite valuable for decisionmakers since they show how real knowledge influences the simulation results. First, it is possible to check how confident the sources were in their evaluations of each criterion and second to identify the overall uncertainty related to the decision (e.g. the choice of a sensitivity level) (Fig. 23).

\subsection{Geographical features of decision-making}

Different geographical decision scales ranging from local to regional have to be considered. Specific decision support systems (DSSs) are therefore expected to adapt the efforts 
Fig. 19 Imprecise and uncertain evaluations are mapped into a basic belief assignment used for fusion
Fig. 20 Evaluation of imperfect information and treatment of the ER-MCDA methodology are fully separated

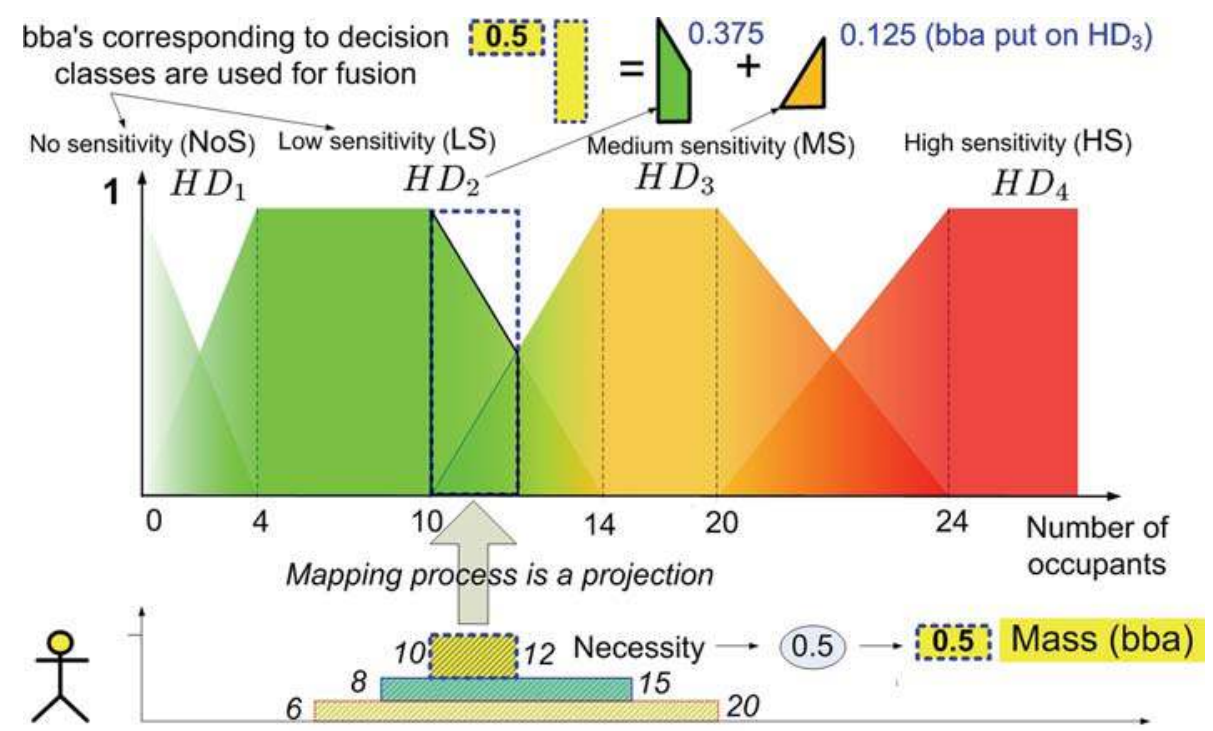

Source no. 1 proposes an imprecise and uncertain evaluation of criterion "Number of occupants" Possibility distribution is projected on the frame of discernment of decision classes (low, medium, high sensitivity)

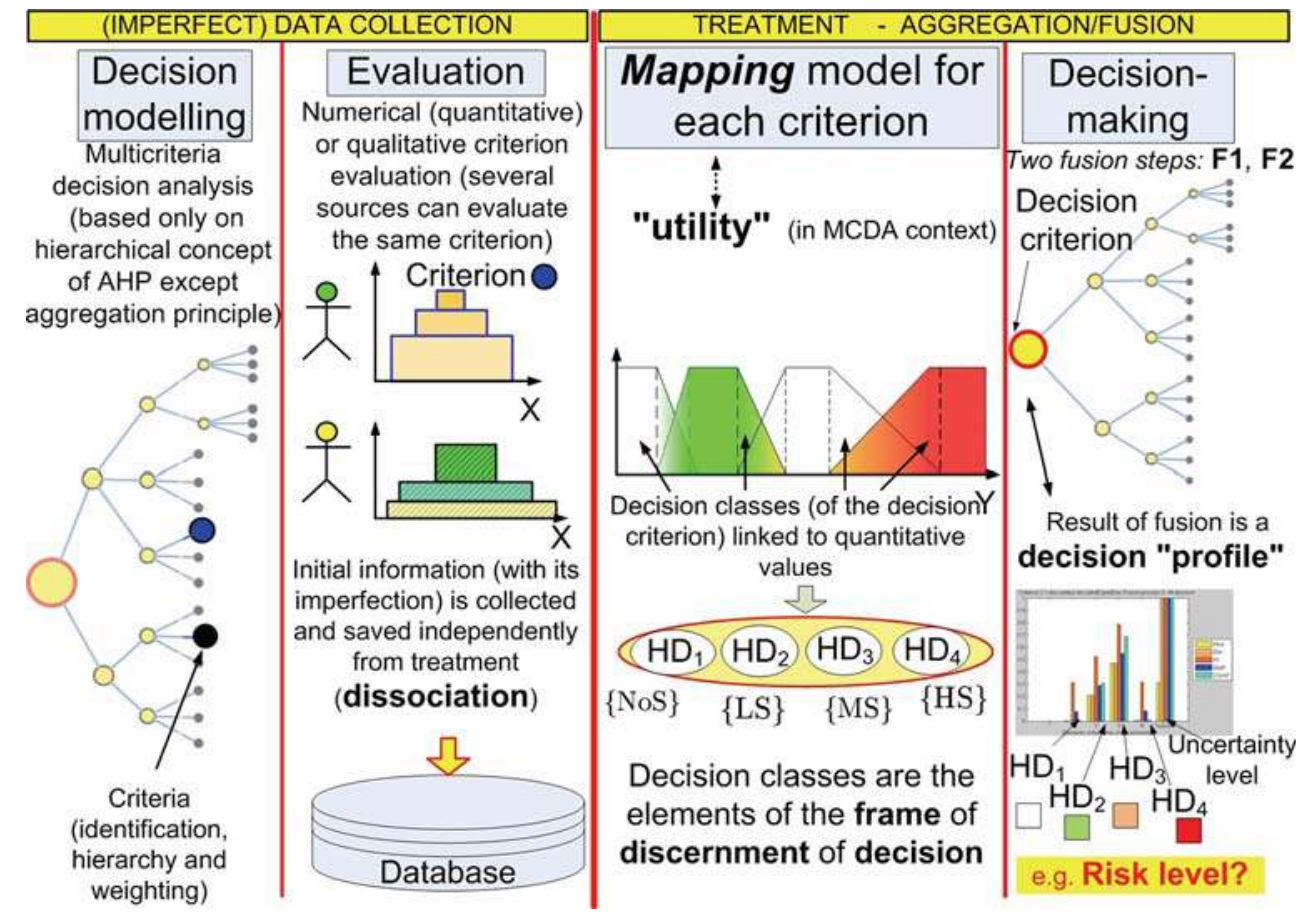

involved to assess hazards, vulnerability, risk and protection works' effectiveness over the entire geographical area studied: quick but inevitably simplified methods are required to identify and prioritise the most important zones to be studied with detailed methods such as local numerical modelling. Global and rapid methods are proposed to identify hot spots over a very wide area (Tacnet 2012): these sites are then investigated in detail at a local scale with specific dedicated methods (Fig. 13). These methods are described with a special and innovative focus on the influence of information imperfection (uncertainty, imprecision) on decision-facilitating methods such as multi-criteria decision methods, numerical modelling.

Spatial information fusion extends the ER-MCDA approach to spatial information with an application to natural risks management problems (Tacnet et al. 2010a) through a combination of available information provided by different sources and to assess information quality (Fig. 24). 
Fig. 21 Evaluation and fusion steps of the ER-MCDA methodology
Fig. 22 Imprecise and uncertain evaluation of criteria are fused together instead of classical AHP aggregation

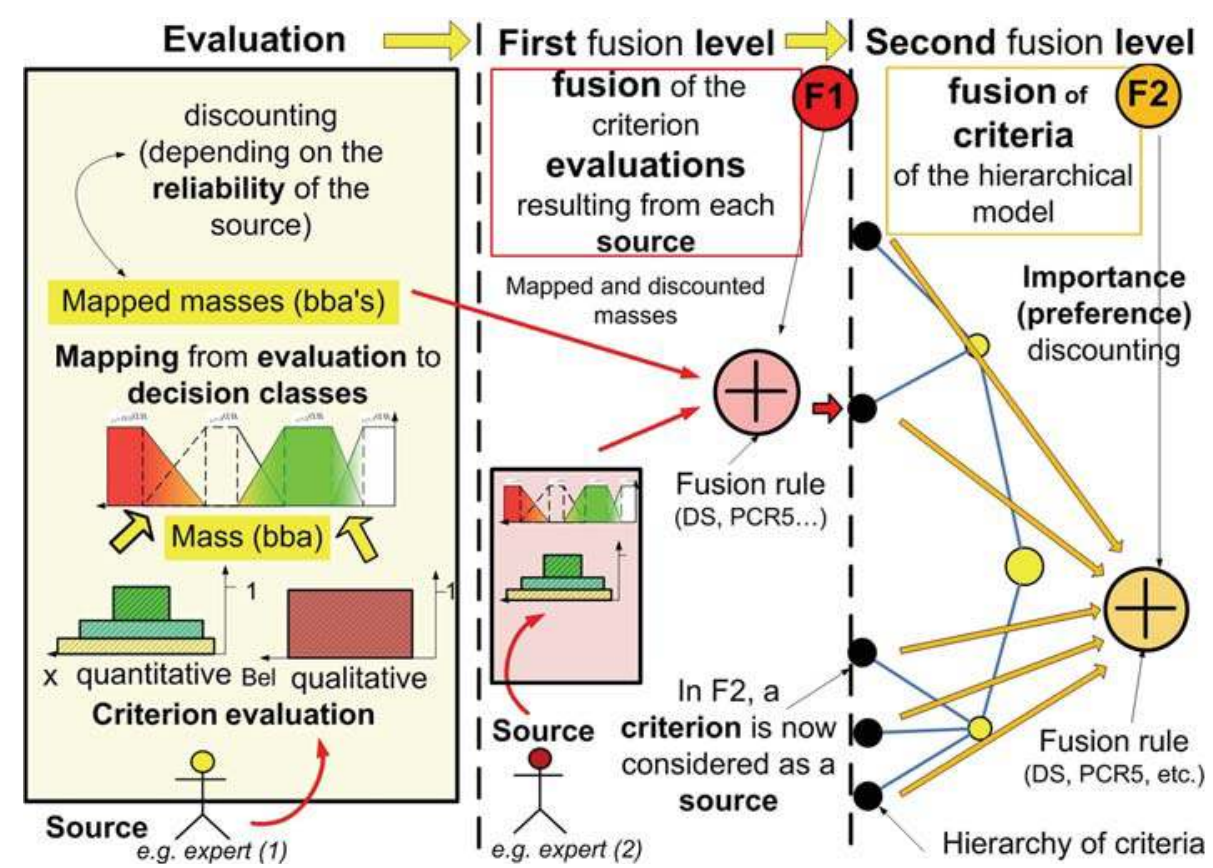

In a single framework, the methodology considers both the uncertainty and imprecision of the spatial extent of information (e.g. debris flows, avalanche extent) as well as its attribute values such as quantitative values (height, speed, volume etc.) or qualitative indexes (reached, not reached). Imperfect information (spatial extent and/or attribute values) is first represented in a GIS. For example, we aim to determine a hazard level using the extent and intensity of a debris flow event. Information comes from sources such as a historical database (imprecise, not fully reliable), expert field analysis (based on an expert judgment) or numerical modelling results (whose uncertainty depends on input data quality). Information is represented through vector and raster approaches. Geographical information (spatial and attribute values) is processed to be introduced in fusion calculation routines using DempsterShafer (DST) (Shafer 1976) and Dezert-Smarandache (DSmT) theories (Smarandache and Dezert 2004-2009). 
Fig. 23 The decision profile traces information quality from criteria to decision
The method provides not only a single choice but also proposes a "decision profile" that informs about information quality level

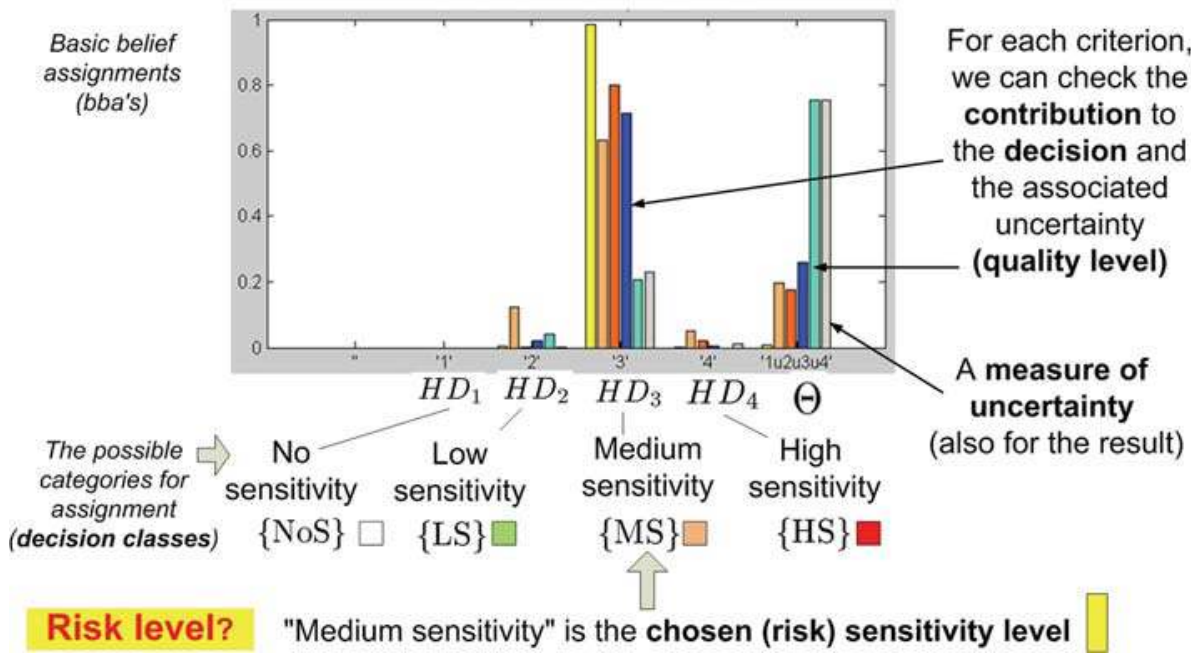

Fig. 24 Principle of spatial fusion of sources in the risk management process

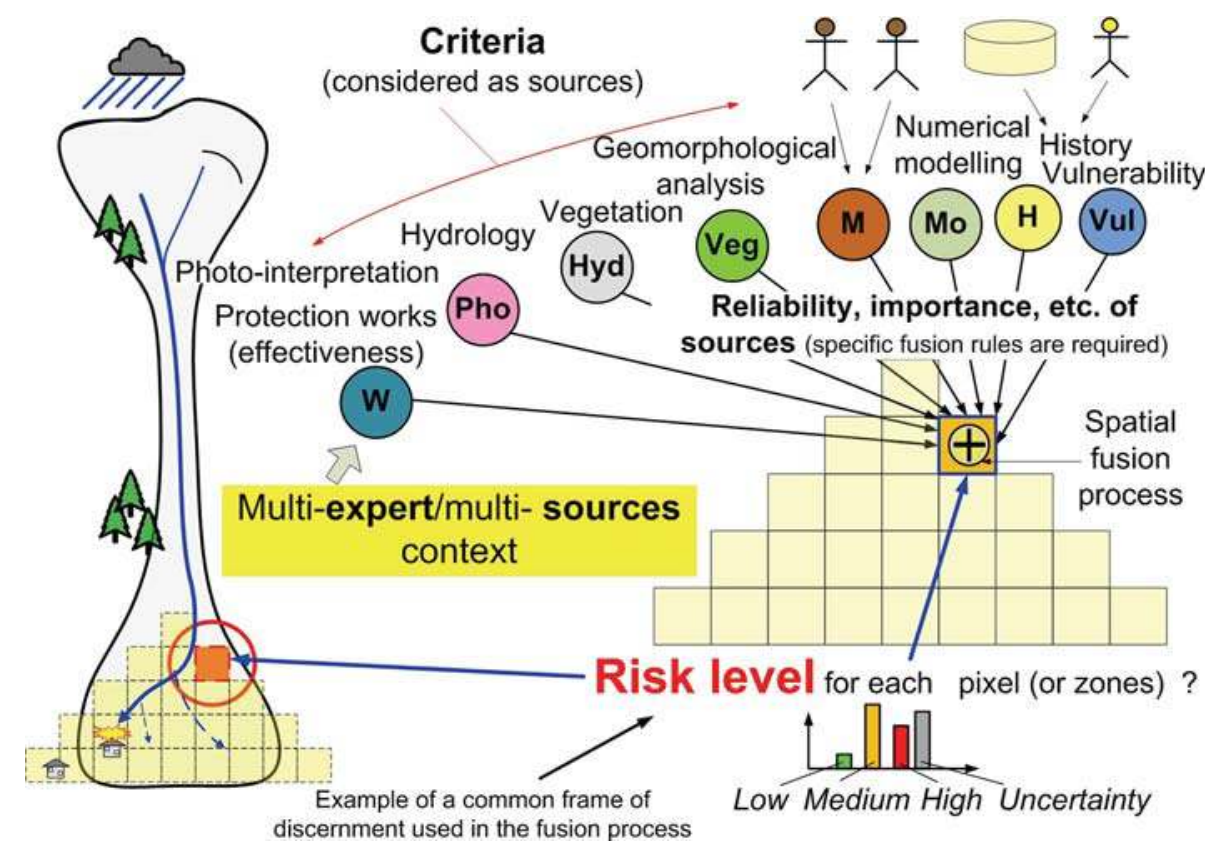

Advanced fusion rules (PCR rules, partial conflict redistribution rules) (Dezert and Smarandache 2006) are used instead of the classic Dempster fusion rule to obtain the combined bba and to take decisions. Finally, we can spatially represent not only hazard (or risk) level, but also a confidence level based on the information quality used to take decisions (Fig. 25).

\subsection{Traceability and information quality in information systems}

Information systems are essential to capitalise expertise processes. In addition to decision-aiding methods, dedicated information systems are an essential part of an integrated framework to collect information used for risk assessment, decision-making and management. Information management implies a continuous chain from data field collection to risk management decisions. Information systems must be designed or adapted to represent the pedigree of data flows (Fig. 26) with respect to existing international standards (ISO 2005, 2010).

Formal knowledge description is an important step for traceability and quality improvement (Fig. 27). Information systems and knowledge-based systems collect raw and processed information and are essential to formalise the 
Fig. 25 Global methodology of spatial information process
(1)

GIS (information input)

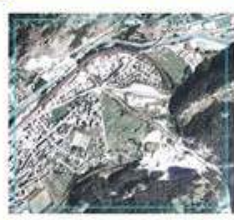

(6)

Representation of decision (intensity, risk level, etc.) with imperfection level in GIS

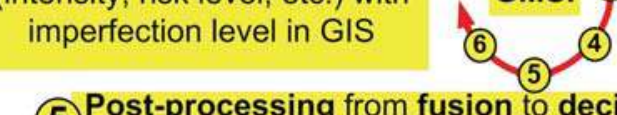

(5) Post-processing from fusion to decision

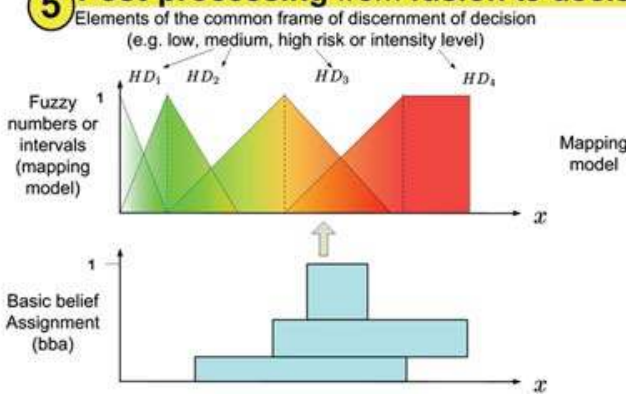

(3)
(2) Imperfect evalutation of information by sources

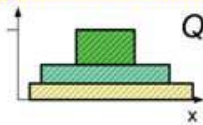

Quantitative data

\section{Spatial extent}

Preprocessing from GIS to fusion model (Raster to Matrix)

(4) External fusion model

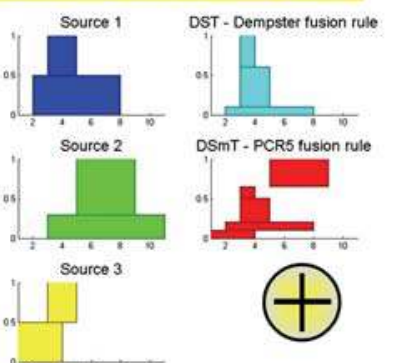

DST, DŚST fusion rules
Fig. 26 Data flow from raw to processed data, adapted from Vidaud-Barral et al. (2010)

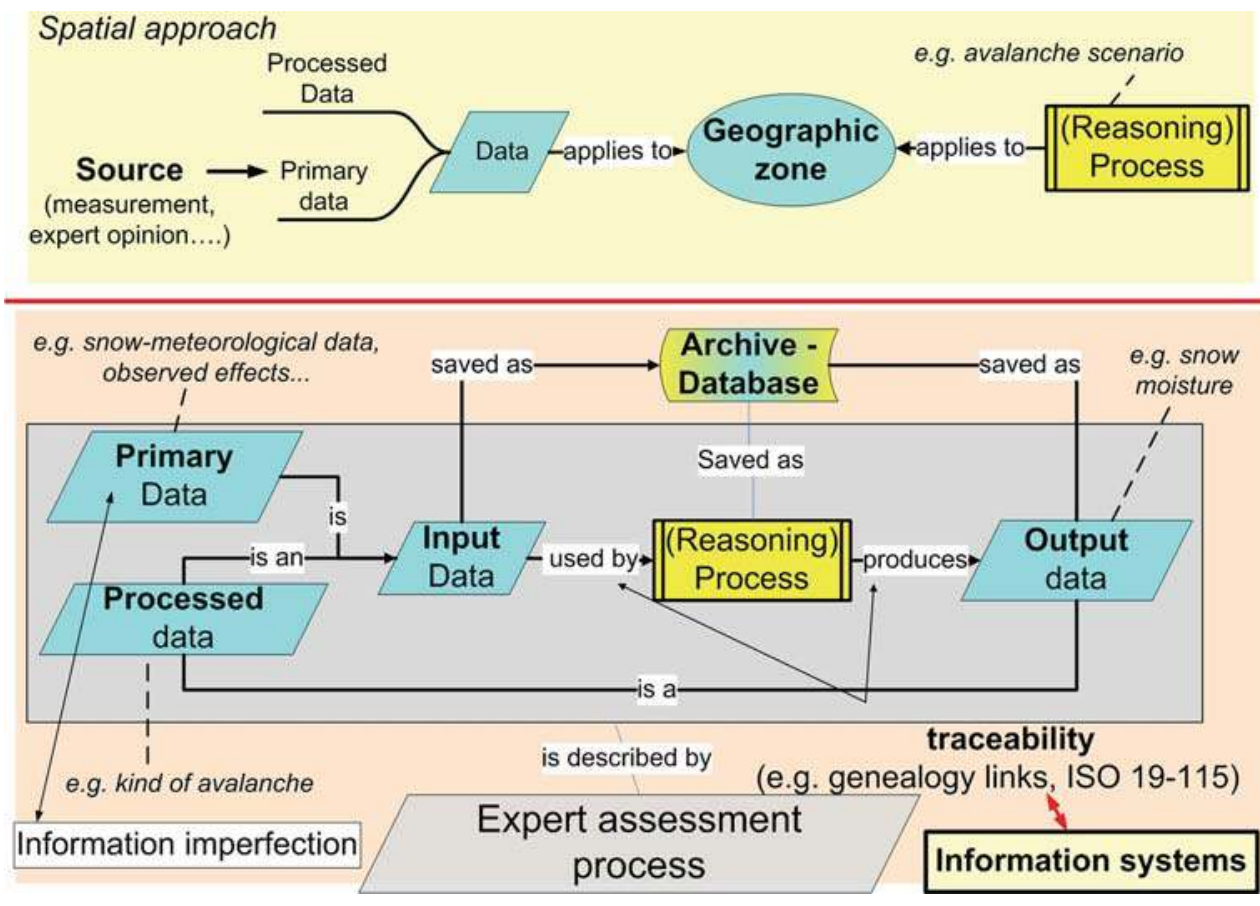

available knowledge coming from all sources and to put information to good use for all decision-makers.

We describe here an example of information quality representation for a snow avalanches database. In France, snow avalanches data come from the French Localisation Map of Avalanche Phenomena (called CLPA in French, see www.avalanches. $\mathrm{fr}^{8}$ ) which provides information on maximum phenomenon extensions (Bonnefoy et al. 2010; Tacnet et al. 2013). Since it records past events, it is used to inform and educate people about the existing areas in

\footnotetext{
${ }^{8}$ Operated by Irstea for the French Ministry of Ecology, Sustainable Development and Energy.
} 
Fig. 27 Traceability of the expert reasoning process (Tacnet and Curt 2010)

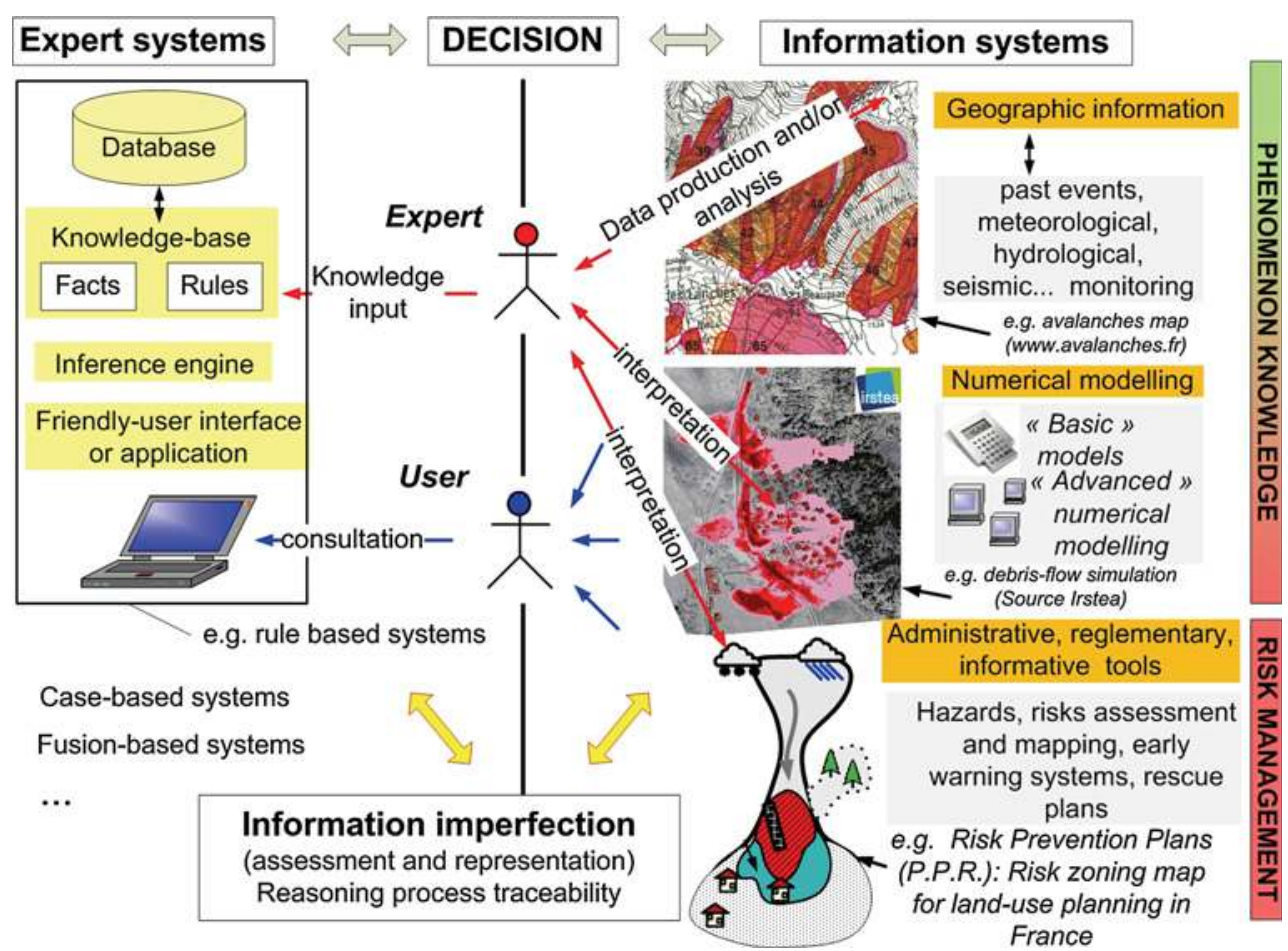

mountainous regions, where avalanches have actually occurred. This database integrates certain features related to information quality description and use. The CLPA records the widest limits of both observed and historical avalanche events as well as past avalanches whose marks remain visible in the field (mainly on vegetation). The extensions of these observed avalanche phenomena are therefore based on oral or written eye witness accounts of events (proven information), and their consequences or on the analysis of aerial photographs supplemented by field analysis. In other cases, photo interpretation is used as another information source (assumed information). On this basis, CLPA has recently been updated to allow spatial analysis based on avalanches limits: lines, corresponding to successive inputs, have been transformed into polygons (Fig. 28). It is now therefore possible to spatially combine the extents with other objects corresponding to housing, networks etc.

Spatial information on snow avalanches (CLPA) includes its quality level: coding rules (Fig. 29) are used to analyse the proven and assumed road exposure (Tacnet et al. 2013). This information quality can be used in recently proposed advanced spatial information fusion methodologies (see Sect. 3.4).

3.6 Linking and adapting industrial and natural riskrelated methodologies

Mitigation actions are based both on non-structural measures such as land-use control and on structural measures

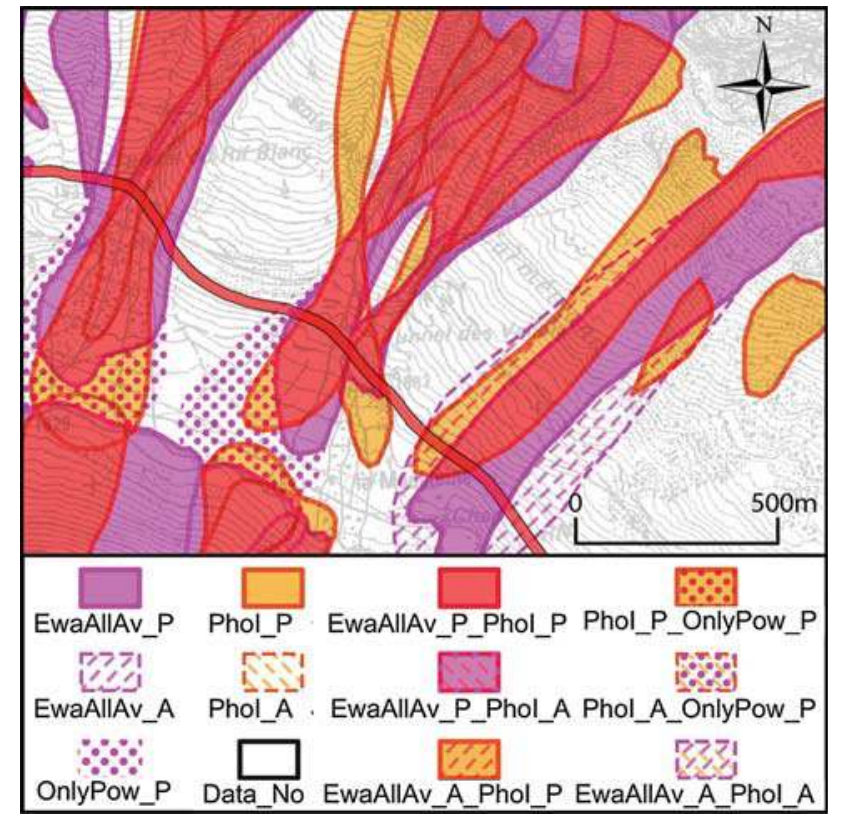

Fig. 28 CLPA spatial zones including quality information (Tacnet et al. 2013)

such as civil engineering protection works (Fig. 2). To prevent or, at least, limit risks, protection works play an essential part in reducing both the causes and effects of phenomena. The analysis of the effectiveness of these protection works is an essential stage of the risk management process (Figs. 2, 13). Decision support tools are needed to take into account both their structural state and 
Fig. 29 CLPA legend with information quality labels (Tacnet et al. 2013)

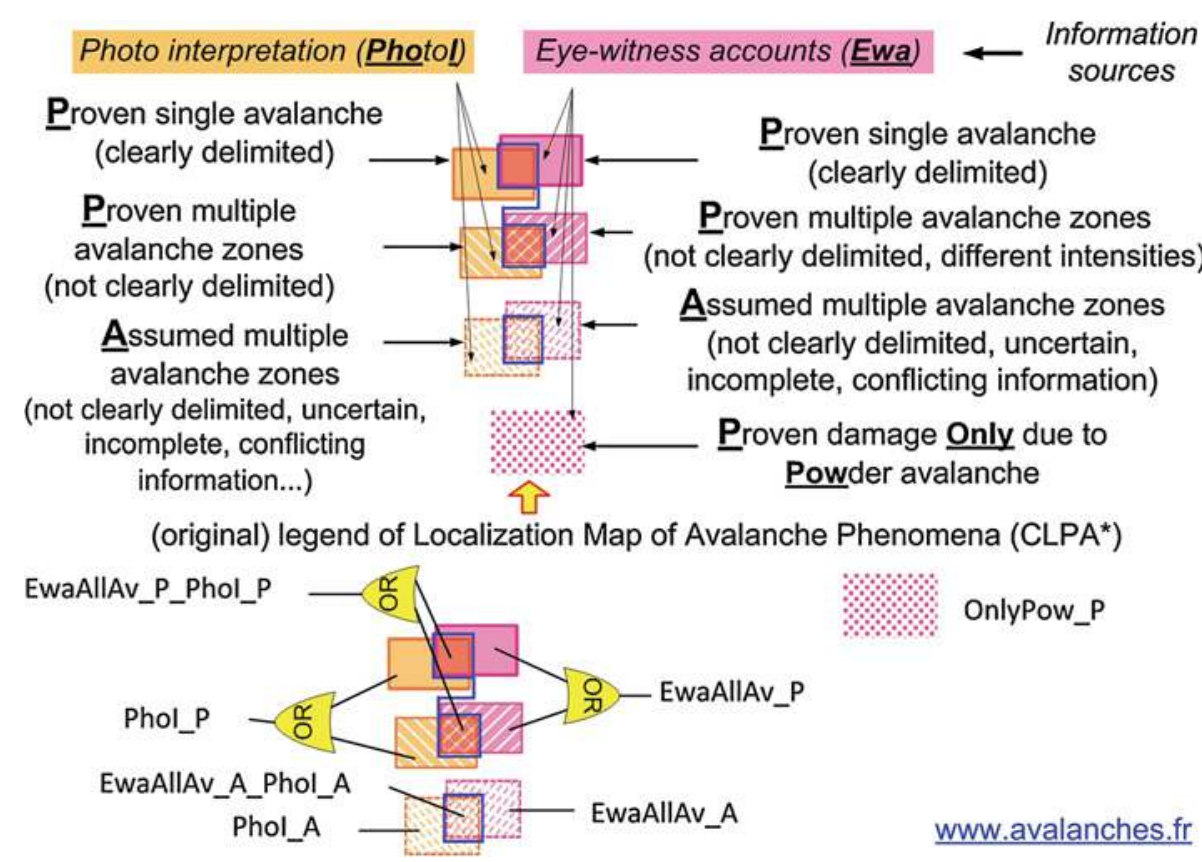

functional effects on phenomena (stopping, braking, guiding, diverting etc.).

Two limit states are usually studied in civil engineering. Serviceability limit states (SLS) concern the components of the structure and design functions that contribute to the functioning of the structure (performance of the drainage function for instance). In the field of dependability, reliability is defined as the ability of a device to perform a required function under given conditions during a given time (Villemeur 1988). This notion reflects the performance of functions although in our case, temporal concepts are not clearly established. The ultimate limit state (ULS) considers the performance of a structure to withstand various failure modes. The relevant functions are the functions of resistance in relation to failure modes: this refers to the concept of safety, defined in the dependability analysis, as the ability of an entity to avoid the occurrence, under given conditions, of critical or catastrophic events (Villemeur 1988). It therefore seems appropriate to use the methods of dependability to study the works of protection against torrential floods.

The concepts of dependability analysis, functional analysis and failure modes and effects analysis (FMEA), have already been used in civil engineering especially for hydraulic dams (Curt et al. 2010, 2011), to describe the systems and analyse their failure modes, but they remain quite new tools for the analysis of the effectiveness of protection works. The classic concepts of dependability have recently been discussed to assess the effectiveness of works protecting against torrential floods (Fig. 30).

A methodology is proposed to elicit the expert reasoning process and evaluate the danger level of the protection works (Tacnet et al. 2012). This methodology is based on combined use of both dependability analysis, an emerging technique for natural hazards domain traditionally used in industrial contexts (Magne and Vasseur 2006), and uncertainty analysis using ad hoc theories to take into account the imperfection of information (Fig. 31).

The use of fuzzy logics is based on the existence of gradual transitions between sets (Fig. 32). It is very relevant for processing symbolic data provided by humana and can combine different types of measures, including digital data from sensors and symbolic data expressed by an expert. Fuzzy intervals and possibility distributions are used to assess the indicators that describe the possible failures and the performance level of disposals. Indicators are defined as information formalised so as to make its use repeatable and reproducible (Curt et al. 2010). They provide indications on a function performance. For instance, the "deflecting angle" indicator participates in the assessment of the performance of the "transmission hydraulic flow" function. In the second step, the performance of functions is aggregated to assess performance related to failure modes.

Their implementation is based first on a system description and on the proposal of indicators related to structural and functional failure modes. Developments related to numerical modelling are supplemented by expert analysis aiming to identify qualitative failure sensitivity (Fig. 32).

\section{Conclusion-discussion}

Improving or inventing methods Information imperfection cannot be separated from the numerous and successive 


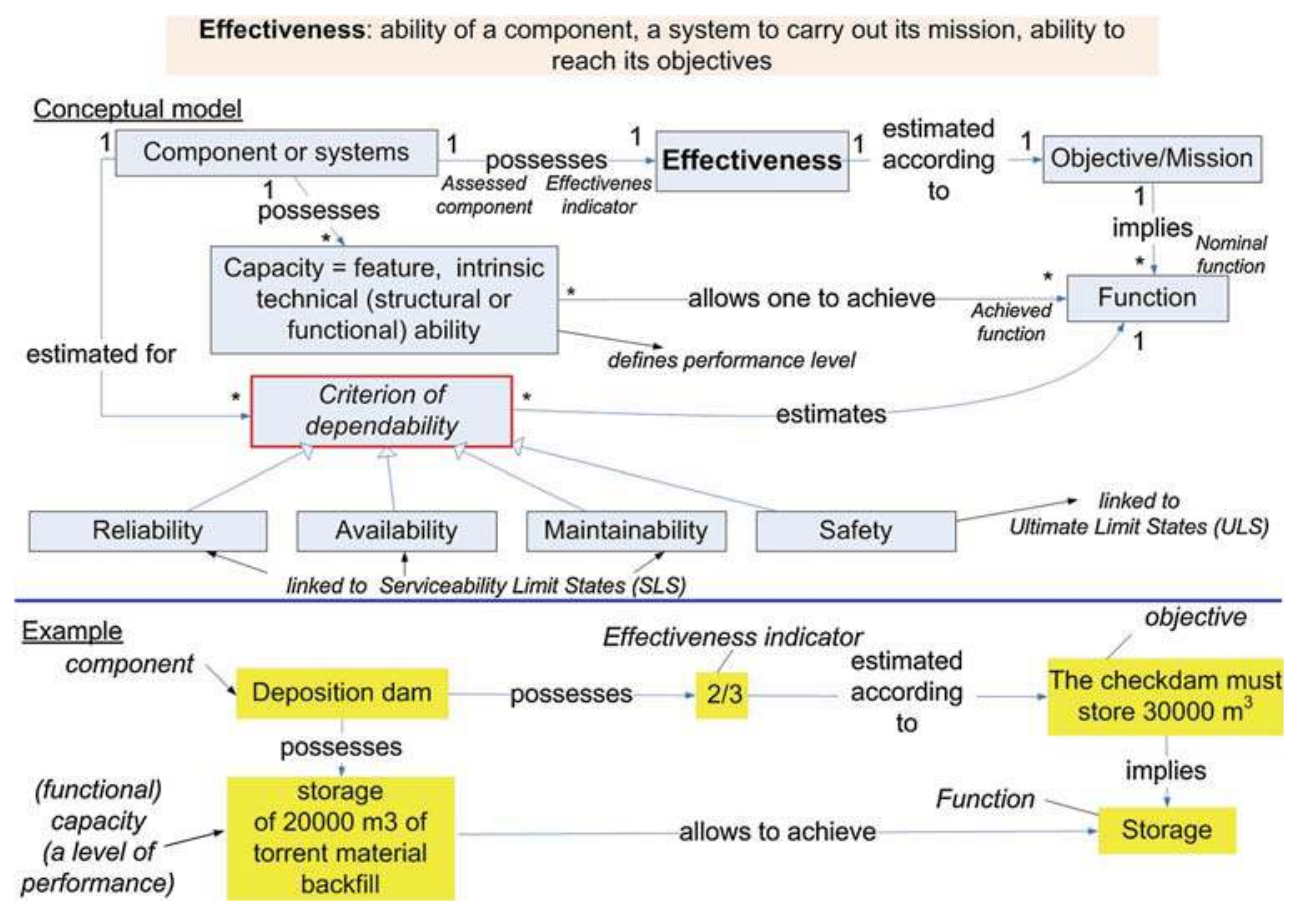

Fig. 30 Definition of the concept of effectiveness, adapted from Tacnet et al. (2012)

Fig. 31 Results of numerical modelling are used as inputs for functional failure scenarios (Tacnet et al. 2012)

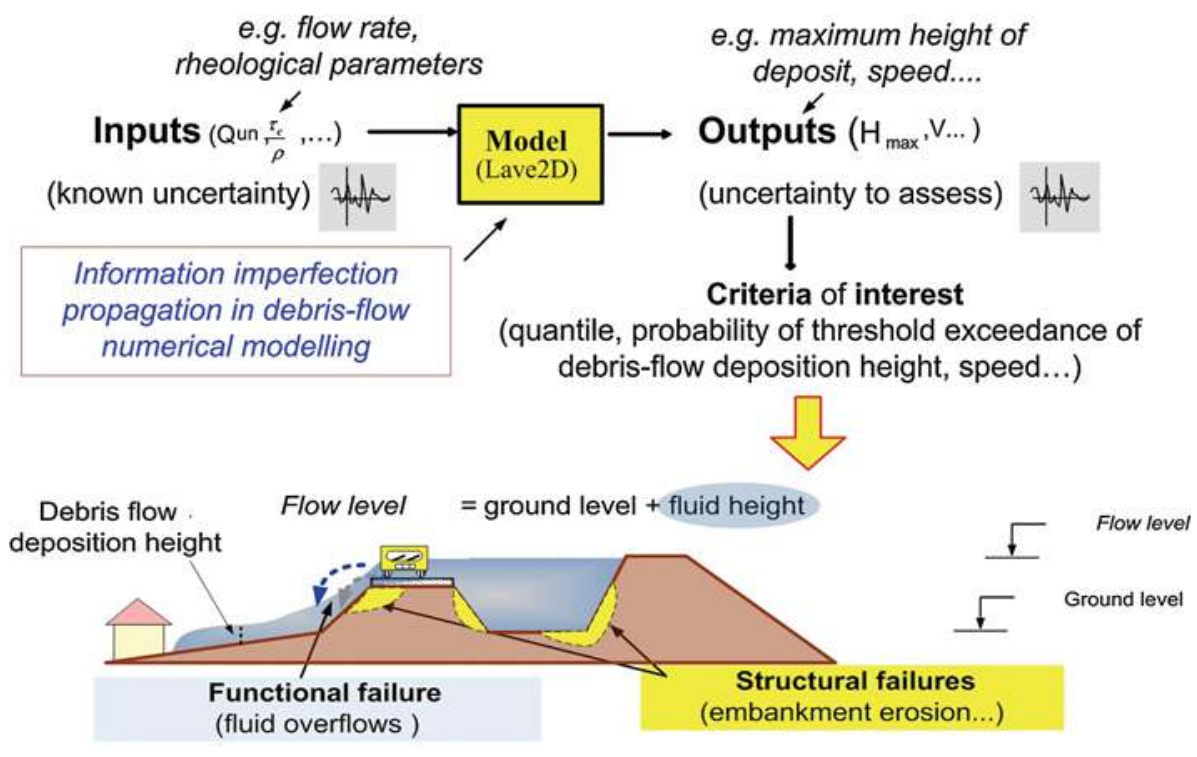

Protection works effectiveness assessment (using dependability analysis) decision processes involved in the risk management process. One must accept this inescapable reality as a basis for decision-aid methods development. Finally, the decisionmakers should be aware that, at every stage of the risk management process, they should never accept and use a single decision-aid method or method that does not consider information imperfection. This paper has presented several ways to implement this idea considering the key issues from decision context identification to developing specific methodologies and using techniques ranging from uncertainty propagation and multi-criteria decision-making to information fusion.

Numerical modelling of natural phenomena is increasingly used in the risk management process. Based on an application to debris flow modelling, the "hybrid approach" using possibility distributions appears to be a flexible tool for 
Fig. 32 Quantitative assessment of functional failures based on fuzzy indicators

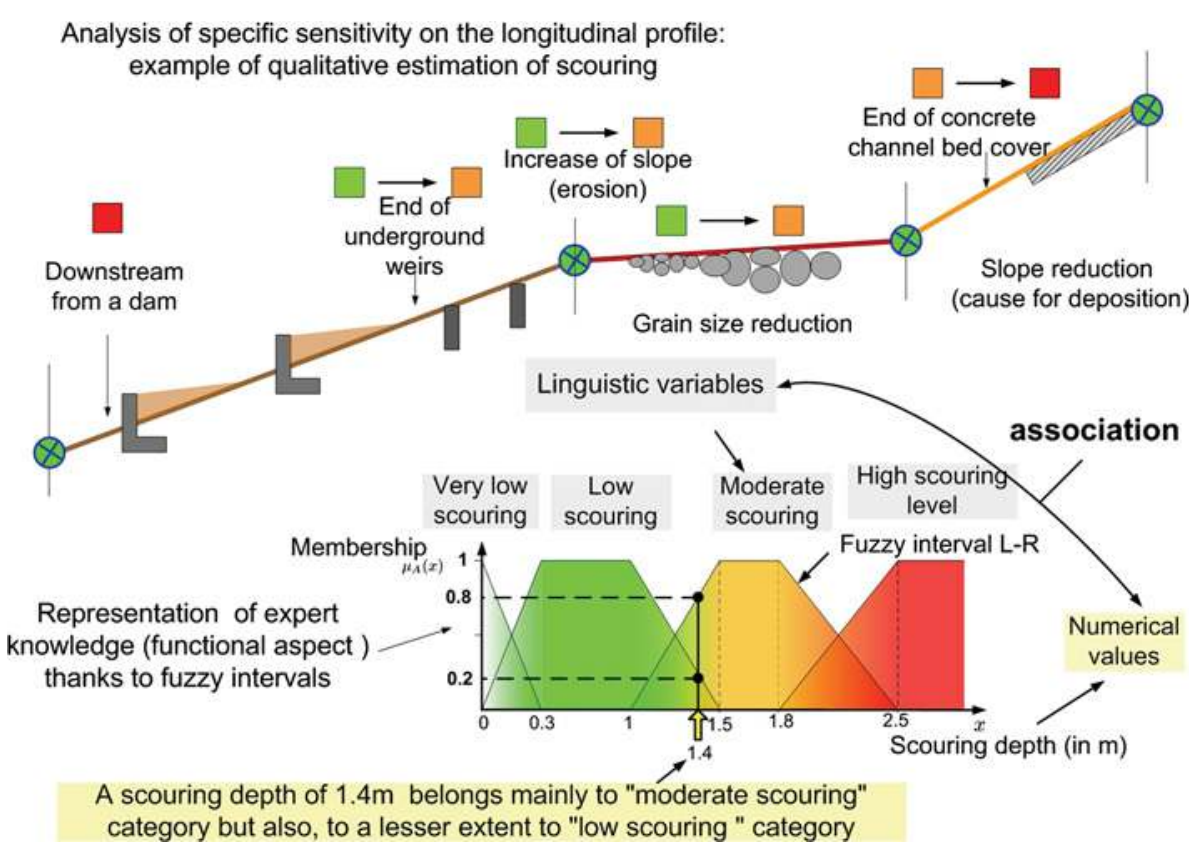

eliciting expert knowledge. The results are helpful for spatial hazard assessment, by quantifying the heights and extension hazard. Instead of few results, we obtain a wide range of simulations showing the influence of input data imperfection on the results. Scientists, technicians and all the stakeholders involved in decision-making should indeed remain aware that any simulation model result closely depends on the quality of the input data used. When knowledge of inputs parameters is poor, they should very carefully consider the decisions based mainly on numerical results. In our opinion, a cautious attitude would consist in generalising ad hoc uncertainty analysis when using numerical modelling, especially when severe consequences are expected such as in the natural hazards context. In ER-MCDA, multi-criteria decision-making methods and information fusion have been adapted to the specific context of natural risks management including spatial applications. Information fusion, which can be extended to a spatial context, is a versatile framework to combine different information sources providing heterogeneous information. Multi-disciplinary convergence of methods coming either from industrial or natural hazards contexts has been explored: dependability analysis can be combined with uncertainty theories and contribute to solving key issues such as protection works effectiveness assessment. However, validation of decision support systems remains difficult because they are specifically designed and developed to handle difficult cases where no obvious decisions can be taken quickly. It is therefore important to develop practical and formal validation processes at each stage of an integrated methodology.

Does communication of imperfection information really help decision-making? The previous developments clearly show the reality of imperfection information and propose a global integrated methodology to consider it in expert assessment and decision-related processes. The classical engineering and technical approaches are supplemented and improved by advanced decision-making methods and information imperfection propagation techniques (Fig. 33).

Information imperfection assessment in the decision process is not new, and the role of experts has already been emphasised (Ravetz 1999). However, consideration of uncertainty and other forms of imperfect information in the expertise process generates a double paradox for the transmitter and receiver of expertise. Recognition and acceptance of uncertainty are never easy. Therefore, if considering information imperfection, such as uncertainty, is part of scientific rigour expected from the expert, it can also be interpreted as a sign of incompetence: this may suggest that looking self-assured even when knowing that information is imperfect should be the best solution to remain credible in the eyes of decision-makers. From another point of view, a decision taken on the basis of imperfect information is obviously more difficult: the decision-maker may prefer to rely on an external categorical decision rather than having to choose within a wider range of possible, but imprecise and uncertain outcomes (the extent of a phenomenon, a risk protection level etc.). This clearly raises the question of uncertainty and more generally imperfection perception depending on the different communities and decision-making contexts. Knowing what is unknown is important to take decisions, but real-life applications are not so easy to implement: how and how far should we finally communicate about the information imperfections to really help rather than complicate decisions? 
Fig. 33 New methodologies are a way to bridge the gap between risk analysis and evaluation
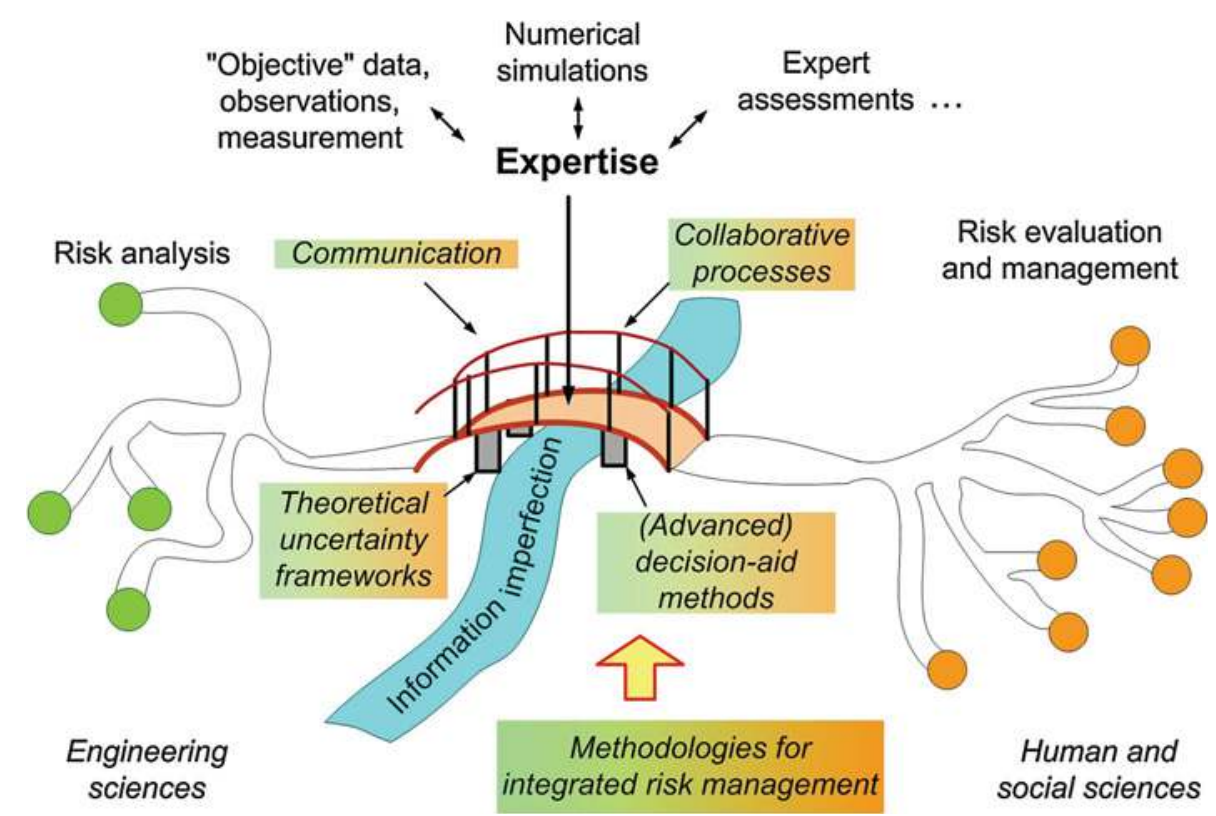

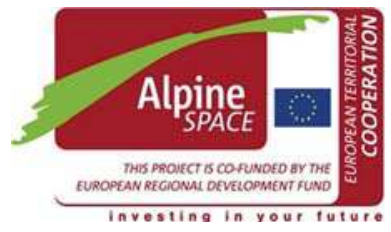

Acknowledgments These developments have been partially funded by the Paramount and StartItUp Project of the European InterReg Alpine Space program.

\section{References}

AFNOR (2003) Norme francaise NF X 50-110—qualité en expertise: prescriptions générales de compétence pour une expertise. Tech. rep., AFNOR (Association Française de Normalisation), SaintDenis La Plaine

Amman W (2006) Risk 21: coping with Risks due to natural hazards in the 21 st century, chap The risk concept. Taylor \& Francis, London, pp 3-23

Baudrit C, Guyonnet D, Dubois D (2005) Postprocessing the hybrid method for addressing uncertainty in risk assessments. J Environ Eng 131(12):1750-1754

Baudrit C, Dubois D, Guyonnet D (2006) Joint propagation and exploitation of probabilistic and possibilistic information in risk assessment. IEEE Transactions on Fuzzy Systems 14(5): 593-608

Bloch I et al (2001) Fusion: General concepts and characteristics. International Journal of Intelligent Systems 16(10):1107-1134

Bonnefoy $\mathrm{M}$ et al (2010) The localization map of avalanche phenomena (clpa): stakes and prospects. In: International snow science workshop proceedings (ISSW) 2010, October 17thOctober 22nd, Squaw Valley, CO, USA

Chojnacki E, Baccou J, Destercke S (2009) Numerical accuracy and efficiency in the propagation of epistemic and aleatory uncertainty. Int J Gen Syst 0:1-23
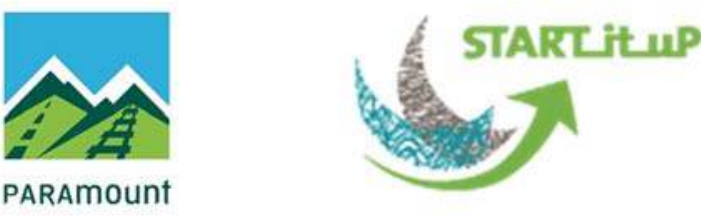

Curt C, Peyras L, Boissier D (2010) A knowledge formalisation and aggregation-based method for the assessment of dam performance. Comput Aided Civil Infrastruct Eng 25:171-183

Curt C, Talon A, Mauris G (2011) A dam assessment support system based on physical measurements, sensory evaluations and expert judgements. Measurement 44:192-201

Dezert J, Smarandache F (2006) Advances and applications of DSmT for information fusion-collected works-volume 2, chap Proportional Conflict Redistribution Rules for Information Fusion. American Research Press, Rehoboth, USA

Dezert J, Tacnet JM (2012) Soft ELECTRE TRI outranking method based on belief functions. In: 15th International conference on information fusion proceedings, 9-12 July 2012, Singapore, pp 607-614

Dezert J et al. (2010) Multi-criteria decision making based on dsmtahp. In: Belief 2010 proceedings of international workshop on the theory of belief functions, Brest (France), 1-2 April 2010

Dubois D, Prade H (1988) Possibility theory: an approach to computerized processing of uncertainty. Plenum Press, New York

Dubois D, Prade H (2006) Concepts et méthodes pour l'aide à la décision 1 -Outils de modélisation, Hermès-Lavoisier, Paris, chap 3-Représentations formelles de l'incertain et de l'imprécis

Dubois D, NGuyen H, Prade H (2000) Fundamental of fuzzy sets. Kluwer, Boston, MA, USA; chap Possibility theory, probability and fuzzy sets: misunderstandings, bridges and gaps, pp 343-438. The handbook of fuzzy sets series

Dupouy G et al (2012) Uncertainty in natural hazards numerical modeling: application of an hybrid approach to debris-flows simulation. In: Proceedings of the 12th international conference Interpraevent, 23-27 April 2011, Grenoble, France

Figueira J, Greco S, Ehrgott ME (2005) Multiple criteria decision analysis: state of the art surveys, international series in 
operations research and management science, vol 78. Springer, Berlin

Helton JC (1997) Uncertainty and sensitivity analysis in the presence of stochastic and subjective uncertainty. J Stat Comput Simul 57(1-4):3-76

ISO (2005) Norme NF EN ISO 19115: 2005-information géographique: métadonnées. Tech. rep., Organisation Internationale de Standardisation (International Organization for Standardization)

ISO (2009) ISO 31000: risk management—principles and guidelines. Tech. rep., International Organization for Standardization

ISO (2010) Norme NF EN ISO 19115-2: 2010-information géographique: métadonnées. partie 2: extensions pour les images et les matrices. Tech. rep., Organisation Internationale de Standardisation (International Organization for Standardization)

Laigle D, et al. (2003) Comparison of numerical simulation of muddy debris flow spreading to record of real events. International Conference on Debris-Flow Hazards Mitigation: Mechanics, Prediction, and Assessment, Proceedings pp 635-646

Magne L, Vasseur D (2006) Risques industriels. Complexité, incertitude et décision: une approche interdisciplinaire, Lavoisier, Paris, chap 9: le risque et sa gestion entre incertitude et ajustement de règles. Collection EDF R\&D

MATE, METL (1997) Plans de prévention des risques naturels prévisibles (PPR)—guide général. Tech. rep., Min. de l'Aménagement du Territoire et de l'Environnement, Min. de 1'Equipement, des Transports et du Logement, France

Merad M et al (2004) Use of multi-criteria decision-aids for risk zoning and management of large area subjected to mininginduced hazards. Tunn Undergr Space Technol 19(2):125-138

Merad M et al (2012) Towards an analytics and an ethics of expertise: learning from decision aiding experiences in public risk assessment and risk management. Cahiers du LAMSADE 326:1-18

Mortureux Y (2001) Techniques de l'Ingénieur-Traité “L'entreprise industrielle", chap La sûreté de fonctionnement: méthodes pour maîtriser les risques-Ref. AG 4 670, pp 1-17

Parsons S (2001) Qualitative approaches for reasoning under uncertainty. Massachusetts Institute of Technology Press, Cambridge

Ravetz J (1999) What is post-normal science. Futures 31:647-653

Renn O, Graham P (2006) Risk governance: towards an integrative approach-white paper $n 1$. Tech. rep., IRGC (International Risk Governance Council), Geneva, Switzerland

Roy B (1985) Méthodologie Multicritère d'Aide à la Décision. Collection Gestion-Série Production et techniques quantitatives appliqués à la gestion, Economica, Paris

Roy B (1989) Main sources of inaccurate determination, uncertainty and imprecision in decision models. Math Comput Model 12(10-11): 1245-1254

Saaty T (1980) The analytic hierarchy process. McGraw Hill, New York

Saltelli A et al (2004) Sensitivity analysis in practice-a guide to assessing scientific models. Wiley, Chichester

Shafer G (1976) A mathematical theory of evidence. Princeton University Press, Princeton

Smarandache F, Dezert J (eds) (2004-2009) Advances and applications of DSmT for information fusion (Collected works), vol 1-3. American Research Press

Smarandache F, Dezert J, Tacnet JM (2010) Fusion of sources of evidence with different importances and reliabilities. In: Fusion 2010 13th international conference on information fusion, Edinburgh, Scotland, 26-29 July 2010

Stewart TJ (2005) Multiple criteria decision analysis: state of the art surveys, international series in operations research and management science, vol 78, chap Dealing with uncertainties in MCDA - chapter 11. Springer, Berlin, pp 445-470

Tacnet JM (2009) Prise en compte de l'incertitude dans l'expertise des risques naturels en montagne par analyse multicritères et fusion d'information. Thèse de Doctorat en Sciences et Génie de l'Environnement, ENSMSE, Saint-Etienne, France

Tacnet JM (2012) (coord.) decision support guidelines-methods, procedures and tools (WP7). Tech. rep., PARAmount project: imProved accessibility: reliability and safety of Alpine transport infrastructure related to MOUNTtainous hazards in a changing climate. http://www.paramout-project.eu/

Tacnet JM, Curt C (2010) Encyclopedia of natural hazards, Springer, Heidelberg, Germany; chap expert (knowledge-based) systems for disaster management, $\mathrm{p}$ (submitted to)

Tacnet JM, Dezert J (2011) Cautious OWA and evidential reasoning for decision under uncertainty. In: 14th International conference on information fusion proceedings, 5-8 July 2011. Chicago, IL, USA, pp 2074-2081

Tacnet JM, Dezert J (2012) Decision support systems-collaborative models and approaches in real environments, lecture notes in business information processing, vol 121, chap new belief function based methods for multi-criteria decision making. Springer, Heidelberg, New-York, Dordrecht, London, pp 103-120

Tacnet JM, Lacroix E (2005) Incertitude et environnement-La fin des certitudes scientifiques, Société d'Ecologie Humaine-EdiSud, Arles 23-25 novembre 2005, chap Risques naturels en montagne: aspects juridiques de l'affichage de l'incertitude dans les expertises, pp 281-291. Colloque Incertitude et environnement

Tacnet JM et al (2010a) Spatial information fusion: application to expertise and management of natural risks in mountains. In: SAGEO 2010, international conference on spatial analysis and GEOmatics, Toulouse, France, 17-19 November 2010, pp 408-412

Tacnet JM, Batton-Hubert M, Dezert J (2010b) A two-step fusion process for multi-criteria decision applied to natural hazards in mountains. In: Belief 2010, proceedings of international workshop on the theory of belief functions, Brest, France, 1-2 April 2010

Tacnet JM et al (2012) Efficiency assessment for torrent protection works: an approach based on safety and reliability analysis. In: Proceedings of the 12th international conference Interpraevent, 23-27 April 2011, Grenoble, France, pp 821-831

Tacnet JM et al (2013) Road network management in the context of natural hazards: a decision-aiding process based on multi-criteria decision making methods and network structural properties analysis. In: Proceedings of the international snow science workshop (ISSW 2013), 7-11 October 2013, Grenoble, France, pp 95-106

Vidaud-Barral L et al (2010) Improving the interoperability and userfriendliness of the french snow avalanche information systems. In: ISSW 2010, proceedings of international snow science workshop, Squaw Valley, CO, USA, 17-22 October 2010

Villemeur A (1988) Sûreté de fonctionnement des systèmes industriels. Editions Eyrolles, Paris

Woo G (1999) The mathematics of natural catastrophes. Imperial College Press, London

Zadeh L (1965) Fuzzy sets. Inf Control 8:338-353

Zadeh LA (1978) Fuzzy sets as a basis for a theory of possibility. Fuzzy Sets Syst 1:3-28

Zwingelstein G (1995) Diagnostic des défaillances-théorie et pratique pour les systèmes industriels. Hermès, Paris 